University of Nebraska - Lincoln DigitalCommons@University of Nebraska - Lincoln

U.S. Navy Research

U.S. Department of Defense

2017

\title{
Influence of fuel on foam degradation for fluorinated and fluorine-freefoams
}

\author{
Katherine M. Hinnant \\ U.S. Naval Research Laboratory, katherine.hinnant@nrl.navy.mil \\ Michael W. Conroy \\ U.S. Naval Research Laboratory \\ Ramagopal Ananth \\ U.S. Naval Research Laboratory
}

Follow this and additional works at: http://digitalcommons.unl.edu/usnavyresearch

Hinnant, Katherine M.; Conroy, Michael W.; and Ananth, Ramagopal, "Influence of fuel on foam degradation for fluorinated and fluorine-freefoams" (2017). U.S. Navy Research. 135.

http://digitalcommons.unl.edu/usnavyresearch/135

This Article is brought to you for free and open access by the U.S. Department of Defense at DigitalCommons@University of Nebraska - Lincoln. It has been accepted for inclusion in U.S. Navy Research by an authorized administrator of DigitalCommons@University of Nebraska - Lincoln. 


\title{
Influence of fuel on foam degradation for fluorinated and fluorine-free foams
}

\author{
Katherine M. Hinnant ${ }^{\mathrm{a}, *}$, Michael W. Conroy ${ }^{\mathrm{b}}$, Ramagopal Ananth ${ }^{\mathrm{a}}$ \\ a Chemistry Division, U.S. Naval Research Laboratory, Washington, DC 20375, United States \\ ${ }^{\mathrm{b}}$ Formerly of the Chemistry Division, U.S. Naval Research Laboratory, United States
}

\section{H I G H L I G H T S}

- Fuel beneath an aqueous firefighting foam increases the rate of foam degradation.

- Iso-octane degrades foams faster than methylcyclohexane.

- Fuel enhances bubble coalescence at the interface increasing foam degradation.

- Fluorinated foams degrade slower than foams with only hydrocarbon surfactants.

\section{A R T I C L E I N F O}

\section{Article history:}

Received 8 December 2016

Received in revised form 22 February 2017

Accepted 24 February 2017

Available online 27 February 2017

\section{Keywords:}

Firefighting foams

Foam degradation

Bubble

Interface

\section{G R A P H I C A L A B S T R A C T}

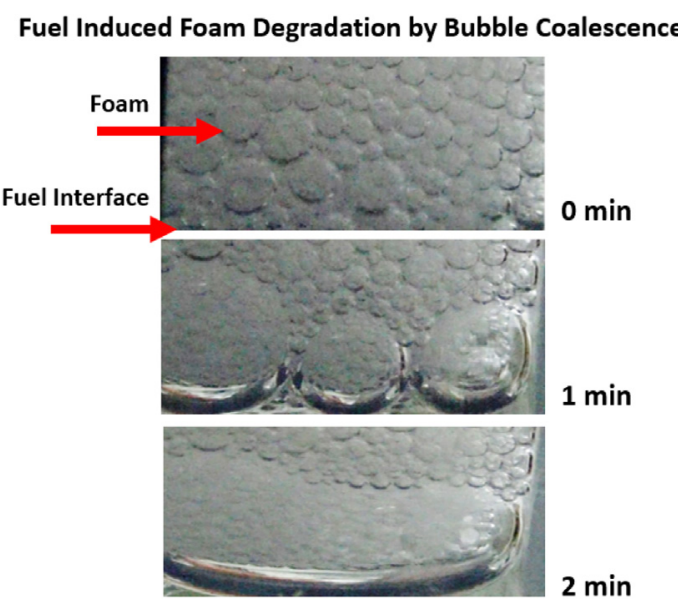

A B S T R A C T

We performed experiments to quantify fuel-induced foam degradation by applying foams onto liquid fuels and water (for comparison) and measuring foam thickness over time. Our investigation included two firefighting foams, one fluorine-free (RF6-ICAO) and the other fluorinated (AFFF), and a foam made with a common surfactant, SDS. We applied a roughly $2 \mathrm{~cm}$ thick foam layer onto three liquid fuels ( $n$-heptane, methylcyclohexane, and isooctane) at room and elevated temperatures. Foam lifetime was reduced by 50 and 75\% for AFFF and RF6 respectively for foams on fuels compared to foams on water at room temperature. For all experiments, the fluorine-free foams (RF6 and SDS) degraded much faster than AFFF. Further, the effect of fuel temperature was significant when the foams were placed over hot fuel: the lifetime of the firefighting foams decreased by 1-2 orders of magnitude between experiments conducted with fuel at room temperature and $50^{\circ} \mathrm{C}$. Prior to the onset of foam degradation over fuels, the firefighting foams experienced a preliminary expansion (by up to $50 \%$ in volume). Video recordings of degradation show that expansion results primarily from bubbles near the interface increasing in size with accelerated coarsening by coalescence. We propose and discuss a mechanism for

\footnotetext{
* Corresponding author.

E-mail address: katherine.hinnant@nrl.navy.mil (K.M. Hinnant).
} 
fuel-induced foam degradation based on our observations. Our results show that fluorine-free RF6 degrades faster than AFFF (by a factor of 3 at room temperature and 12 at elevated temperatures over fuel), which may contribute to differences in their firefighting performance.

Published by Elsevier B.V.

\section{Introduction}

Firefighting foams are used to rapidly suppress and extinguish pool fires in civilian and military applications [1]. The effectiveness of foams is critical to achieve fast fire extinction especially for Navy firefighting applications to prevent weapons cook-off [2]. Weapons cook-off refers to a situation in which exposure to heat from a fire causes on-board weapons to detonate. Foams with fluorinated surfactants, referred to as aqueous film forming foams (AFFF), are able to pass stringent military extinction requirements [3]. However, fluorinated surfactants have been shown to be bio-persistent in the environment and pose health hazards to people [4]. New surfactants have been introduced into foams as alternatives to AFFF, but commercial foams without fluorinated surfactants developed to date have not been able to extinguish fire as quickly as AFFF [5]. In this paper, we will investigate the differences in degradation (reduction in foam volume or foam layer thickness) between fluorinated and fluorine-free foams because foam's effectiveness can be severely deteriorated by foam degradation. Foam degradation can be influenced by many factors including the hot fuel, fire, and foam formulation that contains surfactants and additives needed to generate the foam.

During firefighting, foam is applied to a fuel pool by a nozzle to form a foam blanket over the pool surface. The foam accumulates and creates a physical barrier between the fuel pool and the fire above. As the foam layer builds up, it suppresses vapors from the fuel pool traveling to the fire above, suppressing and eventually extinguishing the flame. Thus, during the firefighting process, the foam is exposed to heat and fuel. The foam layer can degrade as it interacts with the fuel and flame. Degradation can adversely affect a foam's firefighting performance by destroying the foam layer and reducing the foam's ability to block fuel vapors. However, causes for increased foam degradation during firefighting are not well understood. Further, it is difficult to separate the individual effects of fire and fuel on foam degradation in the presence of a fire. In this work, we conducted experiments to quantify degradation of foam floating on a fuel pool, which was maintained at a constant elevated temperature. Experiments were conducted in the absence of a fire to decouple the effects of the fuel from the effects of heat from the fire on foam degradation.

Previous research on foam degradation has focused on understanding the natural aging processes of foam [6-16] and the effect of hydrocarbon liquids interacting with foam [17-23]. The natural aging process is highly dependent on the foam formulation. Researchers have studied the intrinsic aging processes and their effects on foam degradation for a given foam formulation in the absence of fire [6]. Foams naturally degrade over time due to liquid drainage driven by gravity and coarsening. Liquid is held between foam bubbles within the bubble lamellae and in Plateau borders at the junctions of the bubbles. As the liquid drains, the lamellae become thin and rupture causing the bubbles to coalesce. The effects of drainage and coarsening on foam stability for a given foam formulation have been studied [7-16]. These works have elucidated the effect of bubble diameter and coarsening on liquid drainage rates from foam. Both Magrabi et al. [7] and Kennedy et al. [8] determined that larger bubbles, or bubbles that become larger through coarsening, result in faster liquid drainage rates in foams. Kennedy et al. [8] determined that, as bubbles coarsen, the liquid drainage rate increases. Even though many researchers, including Magrabi et al. [7] and Kennedy et al. [8], quantified drainage and coarsening, very few works directly relate liquid drainage and bubble coarsening to foam degradation as measured by the reduction in foam volume with time for firefighting foams.

The effect of heavy hydrocarbons (oil) on the reduction in foam volume (foam degradation) has been studied [17-23] for enhanced oil recovery (EOR) with surfactants commonly used in the petroleum industry. Osei-Bonsu et al. [17] mixed oil with the surfactant solution prior to generation of the foam. Therefore, the oil was dispersed roughly homogenously in the resulting foam. OseiBonsu et al. [17] measured bulk degradation as a decrease in foam column height and bubble-scale degradation in a Hele-Shaw cell for foams with four different surfactants in the presence of long-chain $\left(C_{10}-C_{19}\right)$ hydrocarbons. They found mixed surfactants (cocobetanine and SDS) to be more effective in reducing degradation caused by the oil than individual surfactants by slowing the lamellae thinning. They also found that the smaller the chain length of the hydrocarbon, the faster the degradation for a given surfactant formulation because of increased coarsening rates at the bubble-scale. Vikingstad et al. [18] proposed that the smaller chain hydrocarbons dissolve in micelles and destabilize the lamellae, while the longer chain $\left(>C_{10}\right)$ hydrocarbons form immiscible droplets, which increase lamellae stability. Vikingstad et al. [19] found that the oil had no effect on foam degradation in the presence of perfluoroalkyl betaine (FS-500, DuPont). Simjoo et al. [20] found that a column of foam decreases in height in stages, where the first stage is driven by liquid drainage. The foam column enters a longer second stage, which is driven by coalescence of bubbles rather than Oswald ripening, before reaching a final height. In addition to reducing the surface tension, the surfactant affects the rates of decay in foam column height by changing the stability of a pseudo-emulsion film formed near the lamellae-air interface. Introducing hydrocarbons $\left(C_{6}-C_{16}\right)$ into the foam generating solution had little effect on the drainage but shortened the second stage by speeding up the coalescence of bubbles, and decreased the final height of the foam column. Recently, Osei-Bonsu et al. [21] used a porous glass disc to generate foams with expansion ratios 5-50 (volume of foam per unit volume of liquid). They injected the foam into a Hele-Shaw cell containing silicone oil. They examined the formation of large bubbles due to destabilization of lamellae by silicone oil at a foam-oil interface.

Water evaporation from foam bubbles can also contribute to degradation. Evaporation of water from the foam surface can occur in the absence of heat: dry air in an open container will evaporate foam faster than foam in a closed container where the air is saturated with water. Heat from a fire can dramatically increase the rate of foam degradation through water evaporation; however, limited research has been conducted to quantify the effect of heat. Di Marzo et al. [24] studied the thermal degradation of a $10 \mathrm{~cm}$ thick protein foam layer (expansion ratio, 18) exposed to a radiant heat panel at different radiant heat fluxes. The radiant panel was used to simulate the heat from a fire. They reported degradation as $7.6 \mathrm{~mm} / \mathrm{min}$ regression rate for a foam layer's top surface exposed to a heat flux of $17.5 \mathrm{~kW} / \mathrm{m}^{2}$. They developed a simple model for surface regression based on an energy balance between radiant heat input and 
absorption of latent and sensible heat associated with the water evaporating from the foam surface.

In addition to water evaporation from lamellae, heat can also cause bubbles to expand leading to increased liquid drainage and increased bubble rupture. Lattimer et al. [25] measured the combined effects of fuel and heat on firefighting foam degradation (decrease in foam column height) and the mass of liquid drained from the foam in the presence of a radiant heat source. They conducted small-scale tests with the foam surface exposed to radiant heating panels from above, similar to Di Marzo et al. [24], except that Lattimer et al. placed a JP-5 liquid pool (initially at room temperature) underneath the foam. In their experiments, the average mass evaporation of foam, the rate of liquid drained, and the foam surface regression rate for a fluorinated foam were measured to be $0.18 \mathrm{~kg} / \mathrm{m}^{2} \mathrm{~min}, 2.8 \mathrm{~kg} / \mathrm{m}^{2} \mathrm{~min}$, and $0.0078 \mathrm{~m} / \mathrm{min}$ respectively for a $75 \mathrm{~mm}$ thick foam layer with an initial expansion ratio of 6 and at $20 \mathrm{~kW} / \mathrm{m}^{2}$ radiative flux to the foam surface. Lattimer et al. [25] found that degradation (measured as the decrease in foam column height) was increased significantly by the radiant heat flux due to foam evaporation while the liquid drainage rate was unaffected by the exposure to heat. Their data showed that degradation, evaporation, and drainage occurred at the same time scale in the presence of radiant heat. In comparison, degradation occurred at a much longer time scale than drainage without the exposure to heat. For a $25 \mathrm{~mm}$ thick foam layer, Lattimer et al. noticed foam expanded initially, followed by degradation when the foam was exposed to heat and fuel. Smaller hydrocarbon chain fuels such as heptane may have a different effect on degradation in the presence of heat unlike JP-5. The relationship between fuel properties and foam degradation is not well understood.

In this work, we describe experiments to measure foam degradation and examine the effects of different surfactants used for firefighting foams, small chain-length hydrocarbon fuels, fuel temperature, and initial foam properties such as bubble diameter and expansion ratio. The experiments isolate fuel effects from thermal effects on degradation of a foam layer floating on top of a heated fuel to obtain insights into the causes for enhanced degradation observed during the fire suppression process. Straight chain, branched, and cyclic saturated hydrocarbon fuels having roughly the same vapor pressure were chosen to determine the nature of the interactions between fuel and foam. Commercial fluorinated and fluorine-free firefighting surfactant solutions were chosen to understand the effect of fluorine content on fuel induced foam degradation.

\section{Approach}

We performed control experiments to isolate thermal effects (fuel and water temperature) from the physicochemical effects of fuel exposure to foam. For the room temperature experiments, foam was placed in an empty vial as a control experiment for comparison of foam degradation rates with foams placed over fuel or water. The empty-vial experiment provided the natural rate of foam degradation in the absence of other materials that can dissolve into the foam. Experiments with foams placed over hot water acted as the control for foam degradation at elevated temperatures. Each degradation experiment was repeated three times with a freshly generated foam to determine reproducibility. The associated error bars for the data represents the differences across the three tests.

We provide below a general description of foam degradation measurements to establish context. We detail property measurements for fuels and surfactant solutions used, describe the foam generation method, detail property measurements for the freshly generated foams, and describe methods for measuring degradation at room and elevated fuel temperatures. Despite using an identi- cal foam generation method, foams exhibit different properties and different extents of degradation. To derive a full understanding of fuel induced foam degradation separate from degradation in the absence of fuel, we show differences in properties among fuels, surfactant solutions, and foams in this section.

\subsection{Foam degradation measurement}

Experiments were conducted to quantify foam degradation when placed on top of a liquid fuel surface. We quantified foam degradation by measuring the foam layer thickness over time. We did not consider changes in the "quality" of the foam as indicated by its translucency or density. The liquid drainage from the foam can change the foam's density. However, we did not measure the liquid drainage into the fuel in the small-scale apparatus due to the small amounts of liquid contained in the foam. When the foam was exposed to fuel, we observed the formation of a large bubble near the foam-fuel interface similar to that reported by Osei-Bonsu et al. $[17,21]$. In our experiments, foam is exposed to the fuel at the fuel-foam interface and the large bubble grows to cover the entire fuel surface in the container forming a "gap". A single large bubble or "gap" separates the entire foam layer from the fuel surface in the container. We measured both the size of the "gap" and the total foam layer thickness inclusive of the "gap" volume for the circumstances in which a gap formed. Furthermore, in some cases, the foams expand and become translucent; we report the increase in foam layer thickness as foam expansion rather than degradation.

\subsection{Fuels}

We used $n$-heptane, isooctane, and methylcyclohexane (further referred to as $\mathrm{MCH}$ ) liquid fuels with properties listed in Table 1. Vapor pressure was collected from the MSDS of the three fuels [26-28], the solubility data was collected from the Royal Society of Chemistry [29-31], and the surface tensions were measured with a DuNoy ring tensiometer at room temperature $\left(25^{\circ} \mathrm{C}\right)$. These fuels loosely represent straight-chain compounds, branched, and cyclic compounds found in gasoline and jet fuels. The three fuels selected have similar vapor pressures to eliminate fuel concentration effects on degradation. We also conducted experiments by placing foams onto liquid water, which has a slightly lower vapor pressure than that of the tested fuels. Despite similarities in vapor pressure, there are significant differences in surface tension and solubility in water among the fuels. Fuel solubility in water is important because fuel can significantly affect the surface tension [32] of water contained in the foam.

\subsection{Foams}

The three foams used in this study were characterized for initial bubble diameter, initial bubble distribution, liquid drainage beneath the foam, and initial expansion ratio measured soon after the foam was generated. The bubble diameter can affect foam drainage and coarsening [8], which can affect foam degradation.

The AFFF (Buckeye 3\%, Buckeye Fire Equipment Company, Inc.) used in our experiments is MilSpec [3] qualified and is the most widely used foam for naval firefighting applications. The AFFF surfactant solution is prepared by mixing the concentrate solution provided by the manufacturer with distilled water at 3\% (by volume), which appears color less.

The fluorine-free, firefighting foam, RF6 (Solberg ${ }^{\circledR}$, formerly 3-M Australia) used in our experiments was approved by the International Civil Aviation Organization (ICAO). The RF6 surfactant solution was prepared by diluting the RF6 concentrate solution provided by the manufacturer with distilled water at $6 \%$ (by volume), which appears yellowish brown. 
Table 1

Properties of $n$-heptane, isooctane, MCH, and water [26-31].

\begin{tabular}{|c|c|c|c|c|c|}
\hline Fuel & Chemical Formula & $\begin{array}{l}\text { Molar Mass } \\
\left(\mathrm{g} \mathrm{mol}^{-1}\right)\end{array}$ & $\begin{array}{l}\text { Vapor pressure } \\
\left(\mathrm{mmHg}, 20^{\circ} \mathrm{C}\right)\end{array}$ & $\begin{array}{l}\text { Solubility (mg } \\
\text { fuel } \mathrm{L}^{-1} \text { water, } \\
25^{\circ} \mathrm{C} \text { ) }\end{array}$ & $\begin{array}{l}\text { Surface Tension } \\
\text { (dynes } \mathrm{cm}^{-3} \text {, } \\
\left.25^{\circ} \mathrm{C}\right)\end{array}$ \\
\hline $\mathrm{N}$-heptane & $\mathrm{C}_{7} \mathrm{H}_{16}$ & 100.1 & 39.8 & 3.4 & 19.7 \\
\hline Isooctane & $\mathrm{C}_{8} \mathrm{H}_{18}$ & 114.1 & 40.5 & 2.4 & 19.0 \\
\hline Methylcyclohexane & $\mathrm{C}_{7} \mathrm{H}_{14}$ & 98.1 & 37.0 & 14.0 & 23.4 \\
\hline Water & $\mathrm{H}_{2} \mathrm{O}$ & 18.0 & 23.8 & $\mathrm{~N} / \mathrm{A}$ & 72.0 \\
\hline
\end{tabular}

We also prepared $1 \%$ (by weight) sodium dodecyl sulfate (SDS, Sigma-Aldrich, Inc.) solution by dissolving the powder in distilled water. Even though SDS is not a firefighting foam, we chose SDS for comparison with AFFF and RF6 because SDS has been well characterized in literature. The two firefighting foams, AFFF and RF6, have been used in previous large scale fire testing [5] for evaluating MilSpec performance.

Being commercial products, the precise compositions of the foam concentrate solutions supplied by the manufacturers are proprietary. However, Dlugogorski et al. [33] provided estimates of the composition of RF6 and AFFF concentrates obtained from Australian Companies. Based on the concentrate compositions reported, the MSDS of 3-M AFFF, and the RF6 patent [33-36], we calculated the compositions of $3 \%$ AFFF, $6 \%$ RF6, and $1 \%$ SDS solutions as shown in Table 2. Table 2 shows that the total surfactant concentration in solution is less than $1 \%$ by weight.

AFFF shown in Table 2 pertains to a specific brand and may differ in chemical composition from the formulation used in our work. Table 2 shows that the AFFF formulation has a mixture of hydrocarbon and fluorocarbon surfactants unlike RF6, which is fluorine-free. The hydrocarbon surfactant common in AFFF is diethanolamine lauryl sulfate and the one in RF6 is proprietary. A mixture of hydrocarbon surfactants is commonly used in both AFFF and RF6.

We measured the physical properties of the surfactant solutions at room temperature $\left(25^{\circ} \mathrm{C}\right)$ shown in Table 3 . The density was measured by weighing a known volume of surfactant solution. The viscosity was measured with a glass viscometer (Fisher Scientific Co., $50 \mathrm{~mm}$ minimum depth, model F1426). The surface tension and interfacial tension were measured with a DuNoy ring tensiometer. Interfacial tension between the surfactant solutions and $n$-heptane were measured. The measured density, viscosity, and surface tension agree with properties collected by Kennedy et al. [8] which were collected at $22^{\circ} \mathrm{C}$.

Table 3 shows significant differences in surface tension, interfacial tension, and viscosity among the surfactant solutions used in our experiments. The surfactants and additives increase the viscosity of AFFF and SDS solutions slightly and increase the viscosity of RF6 solution significantly relative to the viscosity $(1 \mathrm{cP})$ of pure water.

\subsection{Foam generation}

Foams were generated using a sparger system shown in Fig. 1. It consists of a nitrogen gas humidifying container on the left and a foam generating container on the right of Fig. 1. The foam generator was fitted with a plastic lid and an exit tube made of a piece of Nalgene braided vinyl tubing, $2 \mathrm{~cm}$ in diameter, $5 \mathrm{~cm}$ long that was attached to the side as shown in Fig. 1. A cylindrical gas sparger (Ace Glass, 4160-09) made of Pyrex glass having pore sizes $170-210 \mu \mathrm{m}$ was used for generating the foam. The sparger was placed inside the $525 \mathrm{~mL}$ foam generator, $3 \mathrm{~cm}$ from the bottom of the container, submerged $6 \mathrm{~cm}$ in depth. To generate the foams, we poured $400 \mathrm{~mL}$ of the surfactant solution into the foam generator on the right in Fig. 1. Humidified nitrogen was fed at a rate of $390 \mathrm{~mL} / \mathrm{min}$ through the sparger in the foam generator to generate bubbles inside the surfactant solution that would rise through a liquid column of $6 \mathrm{~cm}$

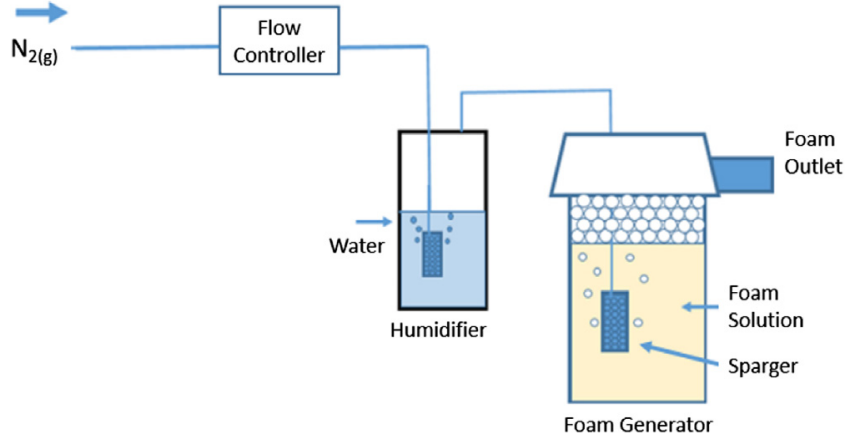

Fig. 1. Diagram of foam generation process.

to the top of the container and dispense through the outlet tube. The height of the liquid column above the sparger is important because it can affect the expansion ratio and liquid drainage rate of the foam. Prior to the foam generator, nitrogen was passed through another sparger placed in liquid water to humidify the nitrogen in a closed glass container. The nitrogen flow rate was controlled with a Sierra Instruments 0-2 L nitrogen flow controller (Model number 840-L-2-0V1-SV1-D-V1-S1). Nitrogen was chosen instead of air to generate the foam to prevent the formation of a flammable mixture of air and fuel for safety. Experiments were also performed using a Pyrex glass sparger having pore sizes 10-20 $\mu \mathrm{m}$ (Ace Glass, Product Number Z408727) to generate foams with smaller bubble diameters. The sparging method used in our bench-scale study is different from the large scale MilSpec method [3] which employs an aspirated nozzle with the surfactant solution fed under pressure to generate foam. As a result, the foam properties such as bubble diameter and expansion ratio can differ significantly between the bench and large scale systems.

\subsection{Foam properties}

The foams were characterized by measuring the initial values for bubble diameter, bubble diameter distribution, expansion ratio, and liquid drainage rate from the foam. All four properties change with time, are dependent on the type of surfactant formulation used, and influence foam degradation. Within $30 \mathrm{~s}$ of generating the foam, we filled a rectangular plastic container $(2.1 \mathrm{~cm} \times 2.1 \mathrm{~cm}$ width and $26.2 \mathrm{~cm}$ height) with foam dispensed from the outlet of the foam generator, and captured an image of the bubbles adjacent to the container wall as soon as the camera focused at the middle region (about $6 \mathrm{~cm}$ height) of the container. A rectangular vessel was chosen to eliminate curvature effects on the recorded images. A Sony HandyCam HDR-CX240 with $29.8 \mathrm{~mm}$ lens, 9.2 megapixels was used to take the image. The image captured half the width of the container and about $1 \mathrm{~cm}$ of foam column height to produce an image with the clearest resolution. We estimate that a $1 \mathrm{~cm}$ high foam column, $1 \mathrm{~cm}$ in width contains roughly $30 \times 30$ bubbles, with 900 bubbles per image. Using a measurement capability in ImageJ, an image processing program, we measured the diameter of individual bubbles against a ruler, which was placed next to the container wall. We analyzed around 300 bubbles for each 
Table 2

Compositions of AFFF [33,35], RF6 [33,34], and SDS [36] surfactant solutions by weight obtained from other works.

\begin{tabular}{|c|c|c|c|}
\hline Material & AFFF FC3002 (\%) & RF6 (\%) & SDS (\%) \\
\hline Water & $98.1-98.5$ & $97.6-98.8$ & 99 \\
\hline Diethyl glycol butyl ether & $0.9-1.2$ & $0.42-0.84$ & $\mathrm{~N} / \mathrm{A}$ \\
\hline Alkyl sulfate salts & $0.03-0.15$ & $\mathrm{~N} / \mathrm{A}$ & $\mathrm{N} / \mathrm{A}$ \\
\hline Amphoteric fluoroalkylamide derivative & $0.03-0.15$ & $\mathrm{~N} / \mathrm{A}$ & $\mathrm{N} / \mathrm{A}$ \\
\hline Perfluoroalkyl sulfonate salts & $0.03-0.15$ & $\mathrm{~N} / \mathrm{A}$ & $\mathrm{N} / \mathrm{A}$ \\
\hline Sodium dodecyl sulfate & $\mathrm{N} / \mathrm{A}$ & $\mathrm{N} / \mathrm{A}$ & 1 \\
\hline Hydrocarbon surfactant & $0.03-0.18$ & $<0.6$ & $\mathrm{~N} / \mathrm{A}$ \\
\hline Thickeners (xanthan gum, sugars) & $\mathrm{N} / \mathrm{A}$ & $0-0.42$ & $\mathrm{~N} / \mathrm{A}$ \\
\hline
\end{tabular}

Table 3

Physical properties for the surfactant solutions at $25^{\circ} \mathrm{C}$.

\begin{tabular}{|c|c|c|c|c|}
\hline Foam & Density $\left(\mathrm{g} \mathrm{mL}^{-1}\right)$ & Viscosity (cP) & Surface Tension $\left(\mathrm{mN} \mathrm{m}^{-1}\right)$ & Interfacial Tension $\left(\mathrm{mN} \mathrm{m}^{-1}\right)$ \\
\hline AFFF & 1.03 & 1.2 & 16.4 & 1.5 \\
\hline RF6 & 1.06 & 2.4 & 26.4 & 3.31 \\
\hline SDS & 1.06 & 1.1 & 37.6 & 6.03 \\
\hline
\end{tabular}

Table 4

Initial average bubble diameters for three foams generated using spargers having pore sizes $170-210 \mu \mathrm{m}$ and $10-20 \mu \mathrm{m}$ at $25^{\circ} \mathrm{C}$.

\begin{tabular}{lllll}
\hline Foam & AFFF & RF6 & 1\% SDS & Sparger \\
\hline Bubble Diameter $(\mathrm{mm})$ & $0.54 \pm 0.1$ & $0.7 \pm 0.3$ & $0.6 \pm 0.1$ & $170-210 \mu \mathrm{m}$ \\
& $0.3 \pm 0.1$ & $0.26 \pm 0.1$ & N/A & $10-20 \mu \mathrm{m}$ \\
\hline
\end{tabular}

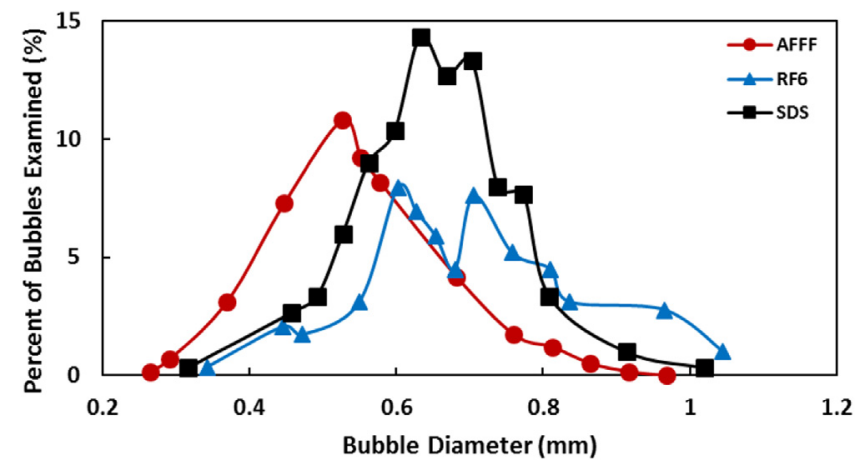

Fig. 2. Initial bubble diameter distribution for AFFF, RF6, and SDS using a sparger with pore size $170-210 \mu \mathrm{m}$.

foam to determine the bubble diameter distribution. For a given foam, we generated foam into the container three separate times and took three images at the same position and calculated the mean foam bubble diameter to determine reproducibility. Table 4 shows the arithmetic average of the three mean values calculated from the three images for a given foam as well as the error which is one standard deviation from the mean value. We note the bubble diameter reported in Table 4 could be affected by the wall of the container and may differ from the true values at the center of the container, not adjacent to wall.

The differences among the initial bubble diameters for different foam formulations seem to be relatively small despite significant differences among the physical properties of the surfactant solutions used to generate the foams as shown in Table 3. However, the bubble diameter differences can become large with time due to differences in the coarsening rates, which are affected by the initial bubble diameter distributions shown in Fig. 2.

Fig. 2 shows the initial bubble diameter distributions measured from one of the three trials of a given foam. The bubble diameters of the 300 bubbles were placed into 13-30 bins to determine the bubble diameter distribution. The bin width was determined by subtracting the smallest and largest of the 300 bubbles and dividing the difference by the expected number of bins. More bins were
Table 5

Initial expansion ratios for three foams generated using a sparger, pore sizes $170-210 \mu \mathrm{m}$ and $10-20 \mu \mathrm{m}$.

\begin{tabular}{lllll}
\hline Foam & AFFF & RF6 & 1\% SDS & Sparger \\
\hline Expansion Ratio & $9.6 \pm 0.3$ & $10.5 \pm 0.4$ & $15.5 \pm 0.1$ & $170-210 \mu \mathrm{m}$ \\
& $6.4 \pm 0.3$ & $5.15 \pm 0.3$ & N/A & $10-20 \mu \mathrm{m}$ \\
\hline
\end{tabular}

added if the distribution was too wide, like in Fig. 3(a). Fig. 2 shows that the bubble diameter distributions differ significantly among different surfactant formulations even though the average bubble diameters differ only by $0.2 \mathrm{~mm}$ in Table 4 . AFFF has a unimodal distribution close to the average bubble diameter shown in Table 4, but also has a large portion of bubbles slightly smaller or larger than the average. RF6 has a bimodal distribution exhibiting two clear peaks in the distribution curves; one peak, slightly smaller than the average diameter, the other peak slightly larger. The bimodal distribution can be seen in all three trial images of RF6 foam as shown in Fig. 3. However, there is significant variation in the position of the two peaks causing a higher standard error of 0.3 in the average bubble diameters of RF6 foam compared to AFFF and SDS foams as shown in Table 4. The large variation among Figs. 2 and 3 in bubble diameter distributions for RF6 foam may be due to inconsistencies in foam generation specific to RF6. RF6 has the widest bubble diameter distribution followed by AFFF with SDS having the narrowest distribution. The bubble diameter distribution can be important because it affects coarsening of bubbles, which can affect foam degradation.

Magrabi et al. [7] and Kennedy et al. [8] measured bubble diameter distributions using foam generation methods different from the sparging technique used in our work. However, Kennedy makes note of the unimodal and bimodal nature of AFFF versus RF6, similar to that shown in Figs. 2 and 3. Using a T-junction to generate foam, Kennedy et al. [8] showed that RF6 bubbles coarsen faster than AFFF, and correlate with the wider bubble diameter distribution for RF6 compared to AFFF. The difference in coarsening rates could relate to foam degradation similar to differences in degradation discussed by Osei-Bonsu et al. [17] for foams used in the context of EOR.

Table 5 below provides the initial expansion ratios for the three foams. The initial expansion ratio was measured by filling a $250 \mathrm{~mL}$ beaker with foam as soon as it was generated (within $10 \mathrm{~s}$ ) and measuring the mass of the foam on a scale. Using the measured foam volume and mass, we calculated the expansion ratio as the volume of foam generated per unit liquid volume of water in the foam. Differences in expansion ratio emulate differences in the initial liquid 


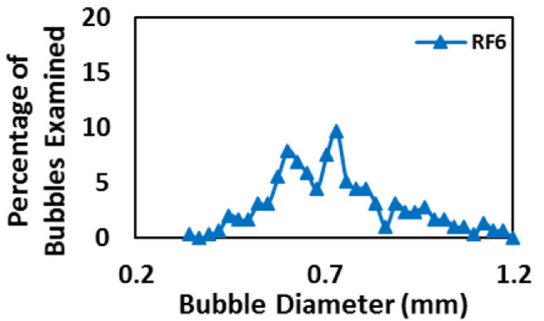

(a)

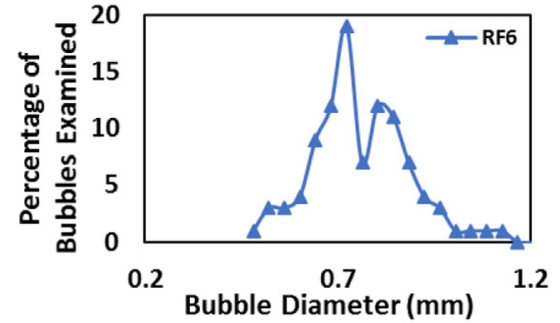

(b)

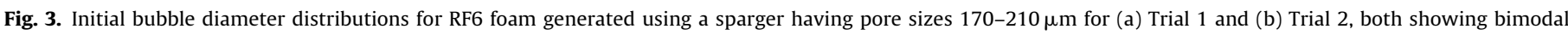
distributions.

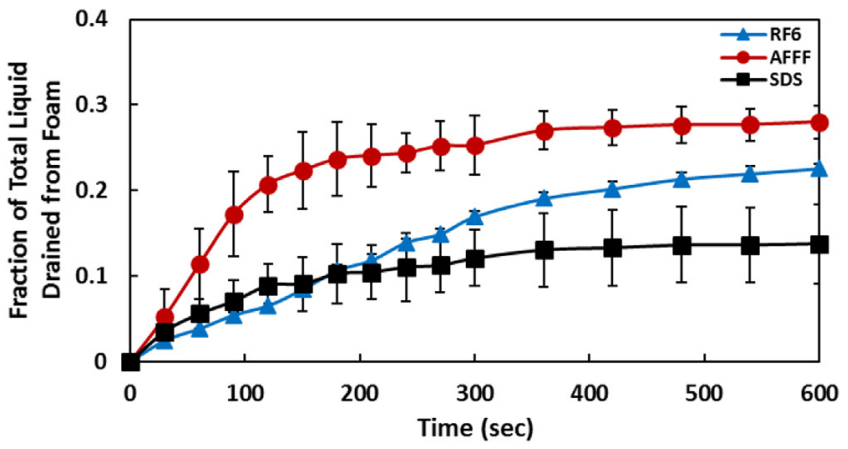

Fig. 4. Liquid drainage from foam over time in an empty graduated cylinder generated using a $170-210 \mu \mathrm{m}$ pore size sparger.

content of the foams, which can contribute to differences in foam degradation.

Liquid drainage from foam is one of the natural aging processes that affects degradation and stability of the foam [7-13]. Fig. 4 shows volume of liquid drained as a fraction of initial volume of liquid contained in the foam with time. For the drainage experiments, a $500 \mathrm{~mL}$ graduated cylinder $37.5 \mathrm{~cm}$ in height, $5 \mathrm{~cm}$ in diameter was filled with foam dispensed straight from the foam generator. The liquid column height that collected at the bottom of the cylinder over time was measured as soon as the foam was generated using a video camera, which records the change in the position of the foam-liquid interface with time. The volume of liquid contained in the foam is determined from the initial weight (or from the initial expansion ratio) of the foam and is used to calculate the fractional drainage with time. Despite differences in the initial expansion ratio and the amount of liquid drained among the three foams, the drainage curves can be scaled based on fractional drainage as shown in Fig. 4.

Fig. 4 shows that AFFF foam has the fastest liquid drainage rate despite AFFF's smaller average bubble diameter shown in Table 4, with RF6 foam having the second fastest rate and SDS foam the slowest liquid drainage rate. The drainage rate is expected to be very sensitive to bubble diameter and the surfactant type, which can affect different bulk and surface properties. AFFF surfactant solution has a smaller bulk viscosity than the RF6 solution as shown in Table 3 which may contribute to the faster liquid drainage rate of AFFF foam. The SDS solution also has a smaller viscosity than the RF6 solution and yet the drainage rate for SDS foam is less than that of RF6 foam. This could be due to a higher initial expansion ratio (or a smaller water content) for SDS foam relative to the RF6 foam as it was shown that the increased expansion ratio decreases the drainage rate [8]. In addition to the bulk properties, the type of surfactant can also affect the surface properties like surface viscosity and surface tension. The differences in surface viscosities of surfactant formulations can significantly influence the drainage rates [11]. The higher drainage rate for AFFF foam rela- tive to RF6 foam was also reported by Kennedy et al. [8] despite differences in the generation methods; Kennedy et al. [8] used a $1 / 2$ inch $T$ junction to mix air and surfactant solution that produced bubbles in micrometers rather than the millimeter bubbles produced in our work. Lattimer et al. [25] reported 214 s for $25 \%$ liquid drainage and 9.7 expansion ratio for AFFF foam, which was generated using a food processing blender; however, 25\% liquid drainage time is $260 \mathrm{~s}$ for AFFF in our work. The drainage rate reported by Lattimer et al. [25] is faster than that shown in Fig. 4 possibly because of differences in the brands of AFFF used and in bubble diameters. Note that the drainage rates shown in Fig. 4 were measured for foams in an initially empty glass container, which corresponds to the control experiment without the presence of fuel.

\subsection{Measurement of foam degradation in the presence of different fuels}

Foam degradation in five scenarios were measured: (1) a control experiment with foam placed in a dry glass beaker (no liquid beneath the foam), and foam placed over a liquid (2) water, (3) $n$-heptane, (4) isooctane, and (5) $\mathrm{MCH}$. The control and water scenarios were conducted to measure the natural rate of foam degradation for reference. The fuel experiments were conducted and compared to the control experiments to isolate the effect of fuel on foam degradation.

Four Pyrex glass $70 \mathrm{~mL}$ vials (one for each of the liquids in Table 1) were each filled with $10 \mathrm{~mL}$ of liquid at room temperature. The vials have a diameter of $3.3 \mathrm{~cm}, 7.5 \mathrm{~cm}$ in height. Using the foam generator described above, a $2.4-2.7 \mathrm{~cm}$ (roughly $10-20 \mathrm{~mL}$ ) thick layer of foam was placed on top of each liquid immediately after generation, and the vials were then filmed side by side until complete degradation of foam occurred. The videos were condensed and analyzed to determine the rate of change in foam thickness for each foam on each liquid.

Separate experiments were conducted to examine the bubble dynamics induced by interactions between the foam and fuel at their interface. Foam and fuel were placed in the rectangular plastic container $(2.1 \mathrm{~cm} \times 2.1 \mathrm{~cm}$ wide $\times 26.2 \mathrm{~cm}$ long $)$ used to measure bubble diameter. A rectangular vessel was chosen to eliminate curvature effects on the recorded images. Fuel filled $9 \mathrm{~cm}$ of the container and the remainder was filled with foam directly from the foam generator. The Sony HandyCam used for bubble diameter measurements was also used to zoom in at the foam-fuel interface with the camera capturing a quarter of the width of the column and $0.5 \mathrm{~cm}$ foam height. This magnification allowed us to record bubbles adjacent to the foam-fuel interface over time and analyze their behavior. The interactions were recorded for AFFF and RF6 foam over room temperature $n$-heptane. 


\subsection{Foam degradation experiment at elevated fuel temperature}

In a pool fire, the fuel is heated from above by the flame to a near boiling point temperature (near $100^{\circ} \mathrm{C}$ for $n$-heptane); therefore, it would be useful to quantify the dependence of foam degradation on fuel temperature. When foam is applied onto a burning pool surface, the foam decreases the pool surface temperature immediately upon contact to about $50^{\circ} \mathrm{C}$ [37]. We therefore conducted experiments to measure degradation at a fuel temperature of about $50^{\circ} \mathrm{C}$.

To study the effect of increased fuel temperature, we performed experiments by placing a $150 \mathrm{~mL}$ glass beaker (diameter $5.5 \mathrm{~cm}$ ) in a water bath controlled by a thermostat to maintain a constant temperature. We then poured $60 \mathrm{~mL}$ of preheated liquid fuel into the beaker using a funnel. Foam was generated and spread into a $1.8-2 \mathrm{~cm}(30-40 \mathrm{~mL})$ layer floating on top of the preheated liquid fuel. We were careful to keep the water bath level just below the foam-fuel interface in the beaker so that the foam is not heated by the water bath directly. A video camera attached to the computer monitored the foam behavior over time (average duration: about $1 \mathrm{~h}$ ). We determined the thickness of foam by measuring the height of the top surface of the foam layer and the liquid fuel surface seen in the recorded video. In the cases where a gas bubble or "gap" lifted the entire foam layer from the liquid fuel surface, we also measured the size of the "gap" from the video and included the height of the bubble in the recorded volume of foam. We believe the gap is a result of foam bubbles bursting and coalescing to form a single bubble that spans the width of the container when in contact with the liquid fuel. Thus, the gap contains the gas that was inside the foam bubbles and may also contain some fuel vapors. Similar to room temperature interface recordings, separate experiments were conducted to investigate the bubble dynamics adjacent to the foam-fuel interface at elevated fuel temperatures. The interactions were recorded for AFFF and RF6 foam over $n$-heptane heated to $50^{\circ} \mathrm{C}$ in the rectangular plastic container.

As the fuel temperature is raised, foam can be degraded both thermally and through increased interactions between the foam and fuel due to higher fuel vapor pressures or vapor concentrations. Experiments with foams floating over heated water served as a standard for the natural rate of foam degradation at elevated temperatures. The hot water experiments isolated the effect of temperature on foam degradation because of the compatibility of foam with water unlike with fuel. The foam degradation caused by the heated water were compared to that over $n$-heptane at elevated temperatures to determine the dependence of foam degradation on fuels at elevated temperatures due to the increased vapor pressure.

\section{Results and discussion}

We describe the results from the foam degradation experiments in this section. We define degradation as a reduction in foam layer thickness regardless of any changes in foam density or "quality". First, we describe the effect of fuel on foam degradation at room temperature by comparing the change in foam thickness over time for foams placed on water and on different fuels. In addition to showing the differences in foam degradation between fuels and water, we will also describe the differences between foams containing fluorocarbon (AFFF) and hydrocarbon (RF6 and SDS) surfactants. We will show similar comparisons among foams and fuels at elevated fuel temperatures. We describe the changes in bubbles in the immediate vicinity of the fuel-foam interface and discuss possible mechanisms of degradation. The size of a single large bubble or "gap" formed near the foam-fuel interface is also reported separately.

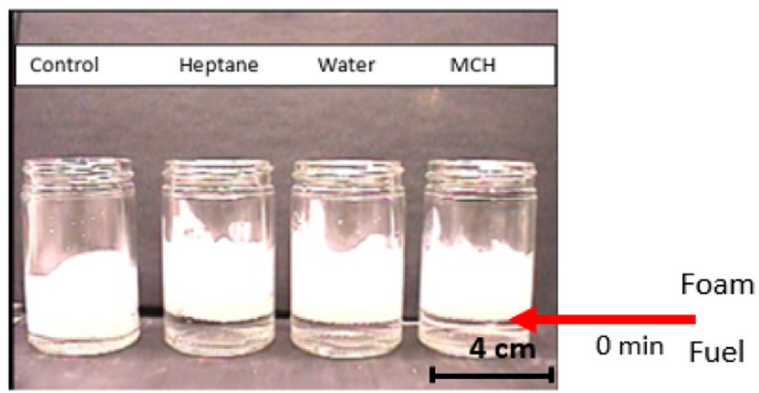

(b)

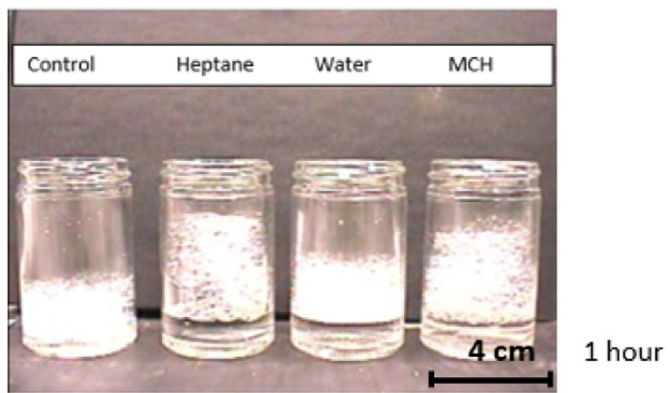

(c)

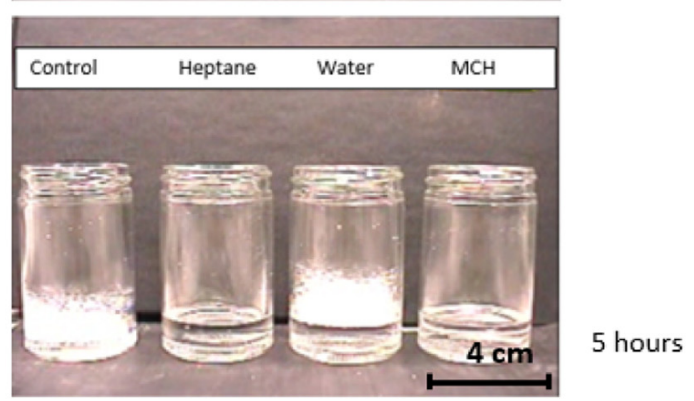

Fig. 5. Images taken of RF6 foam degradation at (a) $0 \mathrm{~min}$, (b) $1 \mathrm{~h}$, and (c) $5 \mathrm{~h}$ with no liquid (control) and over 3 liquids (water, $n$-heptane, and $\mathrm{MCH}$ ) to detail the change in foam thickness over time. The control experiment contained no liquid before foam application. The red arrow in Fig. 5(a) indicates the foam-fuel interface. Initial foam thickness was $2.4-2.7 \mathrm{~cm}$. (For interpretation of the references to colour in this figure legend, the reader is referred to the web version of this article.)

\subsection{Room Temperature experiments}

Fig. 5 shows time-lapse images of a $2.4-2.7 \mathrm{~cm}$ thick RF6 foam layer placed in an empty vial, $3.3 \mathrm{~cm}$ in diameter (control experiment) and over $10 \mathrm{~mL}$ of $n$-heptane, water, and $\mathrm{MCH}$ from left to right. In Fig. 5(a), it is seen that the foams start off at an initial height at time zero. After $1 \mathrm{~h}$, the foam above $n$-heptane and $\mathrm{MCH}$ has expanded while the foam above water and the control experiment has degraded as indicated by the reduction in foam layer thickness. The foam layers over fuel appear more translucent and less dense compared to those in the empty vial or in the vial containing water. In $5 \mathrm{~h}$, the foams over $n$-heptane and $\mathrm{MCH}$ have fully degraded while foam in the control experiment and over water degrade to a lesser degree. Fig. 5 shows that foam layers in contact with water and the glass surface degrade slowly in a similar way without expansion, while the fuels seem to cause the foam to expand first followed by a faster degradation period.

The immiscible nature of $n$-heptane and $\mathrm{MCH}$ in water introduces incompatibility into an aqueous system and could have caused the expansion of foam rather than a decrease in foam thickness and will be discussed later in more detail. We made no measurements of foam quality, only the change in foam height over time. All foams drained water during the $5 \mathrm{~h}$ period, causing the foam layer to become dry. Thus, liquid drainage decreases foam density, which is reflected in the reduced "quality" of the foam seen in Fig. 5(b). A very dry foam is susceptible to evaporation of 


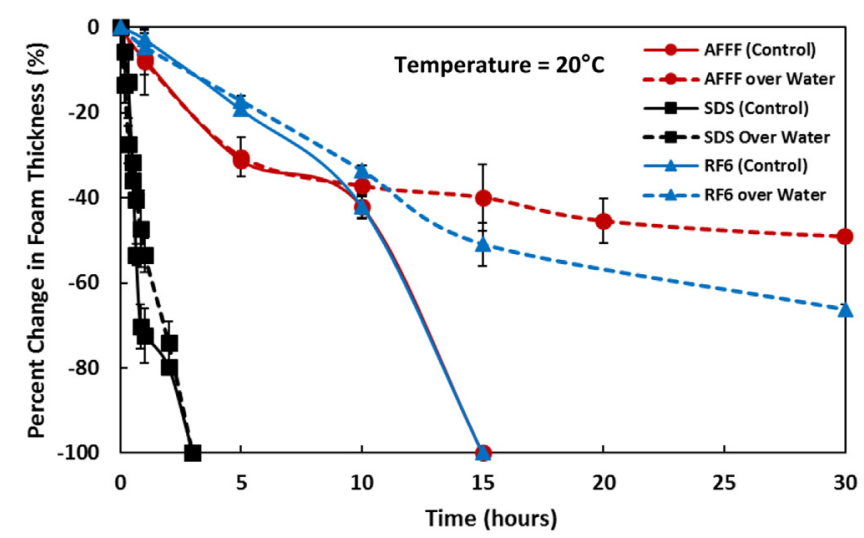

Fig. 6. Foam degradation versus time for the control experiment and foam over water at $20^{\circ} \mathrm{C}$ for SDS, RF6 and AFFF foam. Initial foam thickness was $2.4-2.7 \mathrm{~cm}$.

water in the foam, breakage of bubbles, coalescence, and coarsening contributing to both reduced quality as well as the degradation process. It is possible the liquid drainage could have been affected by the presence of the hydrocarbon liquid underneath. Because of the unevenness of the foam layer as time continued, the foam thickness was measured using Image software at various points along the diameter of the glass vial. This does not account for differences between foam thickness at the front and back (not seen in Fig. 5) of the glass vial; however, differences at various points along the diameter of the foam are relatively small.

Fig. 6 displays the change in foam thickness as a percentage of its initial thickness with time for the three foams. Fig. 6 compares the effects of the foam layer's contact with glass in an empty vial (control) and water surfaces on foam degradation. Foam lifetime refers to the time taken for $100 \%$ degradation of the foam layer thickness.

In the control experiments with no liquid beneath the foam, SDS foam degrades completely within $3 \mathrm{~h}$ while RF6 and AFFF foams degrade completely over 13-15 h. SDS foam has a higher expansion ratio than AFFF and RF6 foams as shown in Table 5. Also, unlike SDS foam, AFFF and RF6 foam contain additives to control liquid viscosity, surface tension, and other properties important to their firefighting performance. The SDS foam degrades faster than RF6 foam despite slower liquid drainage characteristics shown in Fig. 4. Fig. 6 shows that the degradation of AFFF and RF6 foam are very similar in the control experiments despite differences in the surfactant formulation (fluorinated surfactant versus hydrocarbon surfactant and additives) as shown in Table 2.

As seen in Fig. 6, RF6 and AFFF foam degrade at very similar rates in the control experiments wherein no liquid is beneath the foam. However, placing RF6 and AFFF foam over water appears to increase foam lifetime from 13 to $15 \mathrm{~h}$ to more than $60 \mathrm{~h}$ (Fig. 6 only shows up to $30 \mathrm{~h}$ ), with neither foam completely degrading within $60 \mathrm{~h}$. Fig. 6 shows a deviation in behavior between the foams in an empty vial and foams over water around $11 \mathrm{~h}$ when the foams would be significantly dry due to liquid drainage. It is possible that capillary action helps replenish the water lost in the foam by drawing from the water underneath. Mensire et al. [38] conducted experiments with foam solution or olive oil placed under a very dry foam (expansion ratio 833-14285) and monitored the rise of liquid into the foam against gravity due to capillary action. Mensire found that the liquid rose $5.5 \mathrm{~mm}$ upwards into the foam's Plateau borders in $200 \mathrm{~s}$ for monodisperse foams with an expansion ratio of 1408 and a bubble diameter of $1.8 \mathrm{~mm}$. So, it is possible that the liquid water can rise into the foam when it is very dry, replenishing the dryness of the foam, elongating foam lifetime. However, Fig. 6 also shows that the replenishment of water may not have occurred to a significant extent in SDS foam because SDS foam degraded in

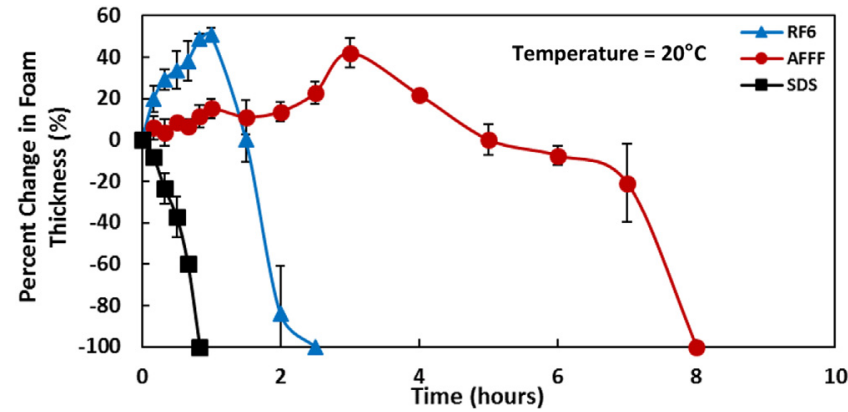

Fig. 7. Foam degradation versus time on $n$-heptane at $20^{\circ} \mathrm{C}$. Initial foam thickness was $2.4-2.7 \mathrm{~cm}$.

$3 \mathrm{~h}$ regardless if the foam was over water or in an empty vial. The foam may have degraded before it became dry enough for capillary rise of the liquid water. This further suggests that degradation is affected by the surfactant formulations. In addition to changes in foam thickness, we looked for any differences in foam quality between the foams in an empty vial and over water. Visually examining the vials in Fig. 5, there is no apparent difference in the foam quality (i.e. translucence) when placed in an empty vial or over water.

Fig. 7 shows that the three foams have a significantly reduced foam lifetime when placed over $n$-heptane (relative to the water and control experiments). Comparing lifetime values of the control experiments in Fig. 6 with those in Fig. 7 shows that the presence of $n$-heptane reduced the lifetime by almost half (from 13 to $15 \mathrm{~h}$ to $8 \mathrm{~h}$ ) for AFFF foam and by a factor of 6 (to $2.5 \mathrm{~h}$ ) for RF6 foam. The fuel effect on foam lifetime is even larger relative to those measured over a water layer. Comparing the lifetimes in Fig. 7 with those for the experiments over a water layer shows that the presence of $n$ heptane reduced the lifetime by more than a factor of 8 (from more than $60 \mathrm{~h}$ to $8 \mathrm{~h}$ ) for AFFF foam and by a factor greater than 25 (to $2.5 \mathrm{~h}$ ) for RF6 foam. Even SDS foam was affected by the presence of $n$-heptane, while the presence of water had little effect on foam lifetime for SDS foam. The lifetime of SDS foam decreased by a factor of 2.5 (from $2.5 \mathrm{~h}$ to $1 \mathrm{~h}$ ) by $n$-heptane as shown in Fig. 7. These are very significant changes in degradation caused by the hydrocarbon fuel.

Before degrading completely, RF6 and AFFF foam expand at short times after being in contact with $n$-heptane as indicated by the increased foam layer thickness shown in Fig. 7. There was no expansion in the case of SDS. Expansion of RF6 and AFFF foams were not seen in the control or water experiment as shown in Fig. 6. As seen in Fig. 5, foam (RF6) over $n$-heptane has much larger bubbles and appears translucent compared to the foams in the dry vial and over water. Heptane is volatile and forms a significant amount of vapor near the foam-heptane interface in a mostly immiscible system. The formation of $n$-heptane vapor could have caused the expansion at the interface initially. As the vapor transports and dissolves slowly into the foam due to its solubility (see Table 1), it may degrade the foam and cause eventual reduction in the foam layer thickness.

We also measured foam degradation for the three foams in contact with liquid isooctane and $\mathrm{MCH}$ (see Table 1 above for a list of the fuel properties). The percent change in foam thickness versus time for AFFF, RF6, and SDS foam at room temperature on the three fuels are plotted in Figs. 8, 9, and 10 respectively. Figs. 8-10 show that the type of fuel impacts foam degradation despite their similar vapor pressures listed in Table 1 . The trend in the degradation behavior for the fuels is consistent for all foams: the shortest foam lifetimes are over isooctane and the longest foam lifetimes are over $\mathrm{MCH}$ regardless of the three surfactant formulations. For all fuels, AFFF and RF6 foam exhibit foam expansion initially but eventually 


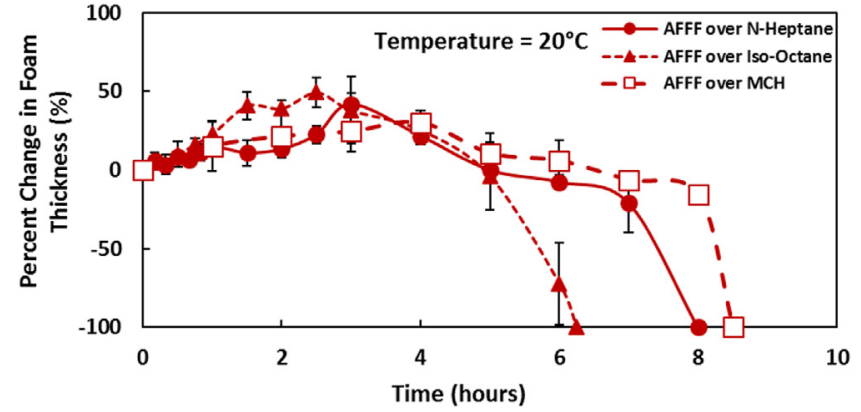

Fig. 8. AFFF foam degradation versus time over three different room temperature fuels $\left(20^{\circ} \mathrm{C}\right)$. Initial foam thickness was $2.4-2.7 \mathrm{~cm}$.

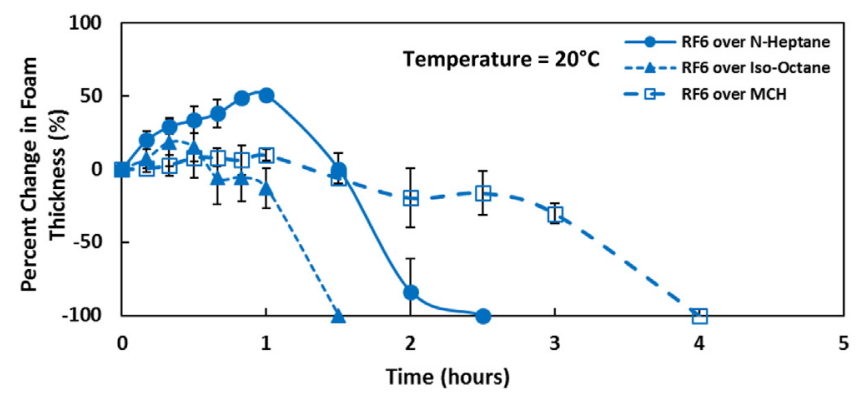

Fig. 9. RF6 foam degradation versus time over three different room temperature fuels $\left(20^{\circ} \mathrm{C}\right)$. Initial foam thickness was $2-2.5 \mathrm{~cm}$.

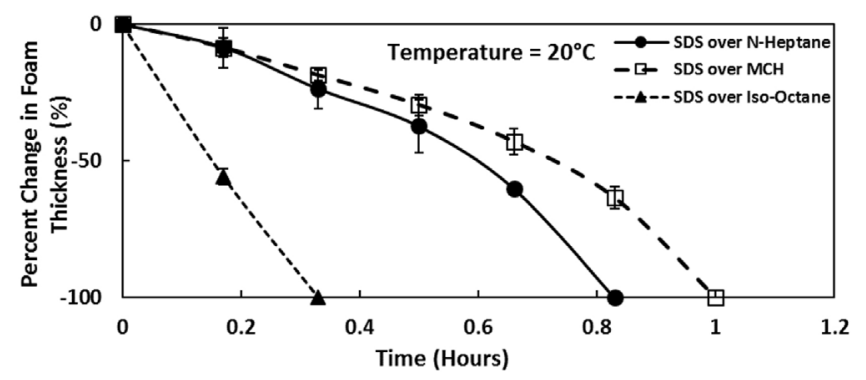

Fig. 10. SDS foam degradation versus time over three different room temperature fuels $\left(20^{\circ} \mathrm{C}\right)$. Initial foam thickness was $2.2-2.7 \mathrm{~cm}$.

degrade unlike SDS foam, which does not exhibit foam expansion. Again, AFFF foam lifetimes are longer than RF6 foam lifetimes with SDS foam having the shortest lifetimes on all fuels considered.

To explore the role of fuel in foam degradation further, we filmed the region near the interface between the foam and the fuel in a separate experiment to determine changes in bubble behavior due to the presence of fuel. Figs. 11 and 12 below are time-lapse images of the interface of the foam over $n$-heptane (top row) and water (bottom row) at room temperature for RF6 and AFFF foam, respectively.

For RF6 foam over $n$-heptane, bubbles at the interface began to grow larger relative to those farther away from the interface. Fig. 11(a) and (b) shows that bubbles grow in time near the interface. We notice from the video that bubbles at the interface grow with time and undergo sudden rupture of lamella separating one bubble from another. As the lamella ruptures, the two adjacent bubbles coalesce. Thus, bubbles appear to expand and then coalesce into each other, forming larger and larger bubbles over time. Fig. 11(c) shows one large bubble as a result of the expansion and coalescence of multiple bubbles. During this period, all bubbles near the interface seem to grow. We did not notice formation of new bubbles by the fuel vapor. The growth continues until all bubbles coalesce into one bubble spanning the region captured by the video camera. For the same time frame, the water-foam interface shown in Fig. 11(d-f) is relatively calm, devoid of the dynamics that form large bubbles compared to Fig. 11(a-c). We did not see the rapid lamella rupture in foams over water that is seen with foam over $n$-heptane. The foams exposure to fuel clearly is affecting bubble growth and coalescence. The streaked lines in Fig. 11(d-f) are small distortions in the corner walls of the plastic container that become visible through a transparent liquid at high magnification.

Video evidence focused on a portion of the interface, but the entire foam layer was observed for qualitative understanding of foam degradation. We noticed that bubbles at distances farther (not shown in Fig. 11) from the interface also became larger for RF6 over $n$-heptane and over water, but at a much slower rate than the bubbles at the foam-fuel interface. This bubble growth away from the interface may be the result of classical Oswald ripening $[7,8,14-16]$ (or classical coarsening), an expected form of foam aging with time due to diffusion of gas from small bubbles to large bubbles. In Oswald ripening, small bubbles decrease in size and large bubbles increase in size. However, the coalescence of bubbles seen at the interface is different from the diffusion-based coarsening mechanism occurring in the control experiment as discussed by Magrabi et al. [7] and Kennedy et al. [8]. Using Kennedy's coarsening equations and considering the initial bubble diameters to be $0.7 \mathrm{~mm}$ for RF6 foam and $0.54 \mathrm{~mm}$ for AFFF foam, the bubbles' diameters are predicted after $30 \mathrm{~min}$ to increase to $1.4 \mathrm{~mm}$ for RF6 foam and $0.96 \mathrm{~mm}$ for AFFF foam in the control case without a fuel. In Fig. 11(b), the large bubble at the fuel-foam interface after $30 \mathrm{~min}$ is about 3 times larger than $1.4 \mathrm{~mm}$. In comparison, the foam over water has bubble diameters roughly $1 \mathrm{~mm}$ at $30 \mathrm{~min}$ as seen in Fig. 11(e) and are closer to the predictions of Kennedy et al. [8]. Thus, the change in bubble diameter at the interface does not seem to be described by the classical gas-diffusion-coarsening dynamics for RF6 foam above $n$-heptane unlike that on water.

The coalescence of bubbles near the foam-fuel interface is also seen for AFFF foam in Fig. 12, but at a slower rate than shown in Fig. 11 for RF6 foam. Again, bubbles at the foam-water interface seem to grow to about the same size (about $1 \mathrm{~mm}$ ) comparable to that expected from the classical diffusion driven coarsening as shown in Fig. 12(d-f).

Large bubbles begin to form at the interface for AFFF foam in Fig. 12(a-c). Comparing Figs. 11 and 12, in an hour, RF6 foam forms one large bubble over the recorded region of the interface while AFFF foam still has multiple bubbles that have yet to coalesce into one bubble. The coalescence near the foam-fuel interface at room temperature was noted by Osei-Bonsu et al. [17] and Simjoo et al. [20] for SDS and other foams used in the petrochemical industry for EOR. They showed degradation was caused by coalescence when the foams were homogeneously mixed with alkane fuels rather than due to Oswald ripening of bubbles and that the large bubbles contained the volume of gas in the smaller bubbles before they coalesced. They showed that the bubble coalescence occurred with short chain (ten carbon length or less) alkane hydrocarbons, which had higher mobility in the aqueous phase relative to heavier hydrocarbons. For long chain hydrocarbon fuels, they reported an increase in foam stability. In future work, it would be interesting to examine degradation of firefighting foams in contact with heavier fuels. Recently, Osei-Bonsu et al. [21] examined the foam-oil interface in a Hele-shaw cell and observed formation of large bubbles due to rupturing and coalescence of smaller bubbles by the oil. This caused foam destruction similar to the events depicted in Figs. 11 and 12. When they replaced oil with water, the large bubble growth was not observed at the foam-water interface similar to the observations in our experiments when the foams were placed over water. 

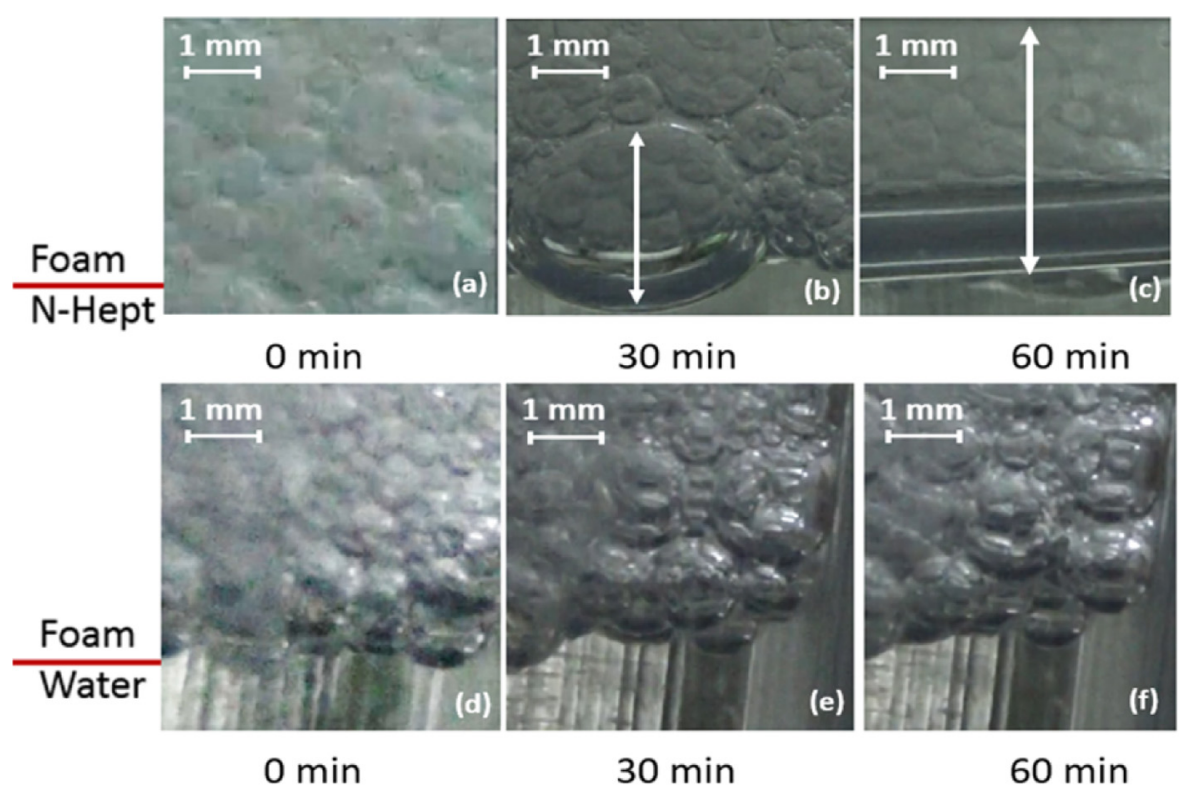

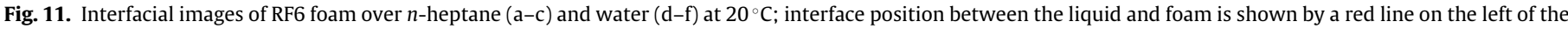

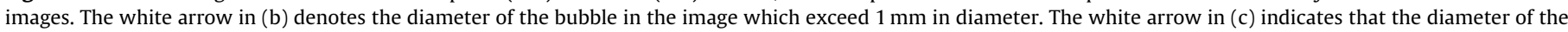
bubble extends beyond the captured image. (For interpretation of the references to colour in this figure legend, the reader is referred to the web version of this article.)
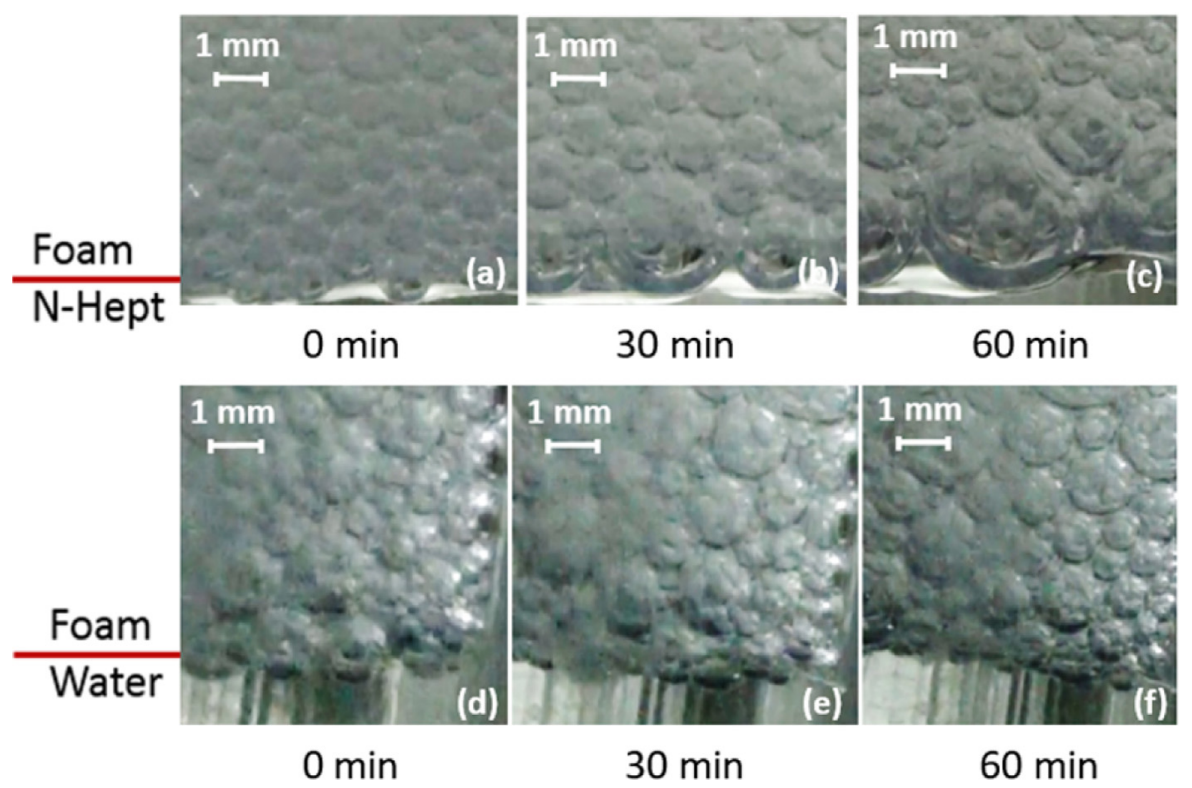

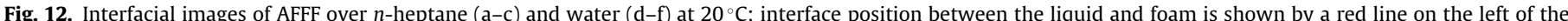

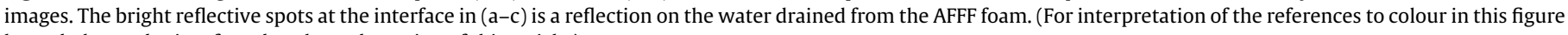
legend, the reader is referred to the web version of this article.)

\subsection{Elevated temperature effects}

We studied the effect of fuel temperature on foam degradation by heating the fuel externally to observe foam degradation at more relevant temperatures for firefighting. Measurements conducted at room temperature showed degradation taking hours; but, in fire suppression, degradation will be important on time scales of minutes. Because of the short lifetime of SDS, foam degradation for SDS was not measured at elevated temperatures in this work. Foams were placed over hot fuel and hot water to isolate the thermal effect on foam degradation. The elevated liquid temperature increases the amount of vapor formed at the interface significantly. Because water will not transport (in net terms) through the already aqueous foam, only heat will be transported through the foam. Because fuels can transport through the foam, the foam may be affected by the temperature or through new interactions with the fuel. By comparing the degradation to foam over fuel and water, we can separate these effects. Fig. 13 shows time-lapse images from AFFF and RF6 placed on hot $n$-heptane at $50^{\circ} \mathrm{C}$.

In our experiments, $30-40 \mathrm{~mL}$ of foam initially at room temperature is placed over $60 \mathrm{~mL}$ of hot (preheated) liquid fuel or water in a $150 \mathrm{~mL}$ glass beaker ( $5.5 \mathrm{~cm}$ diameter and $8 \mathrm{~cm}$ height). The liquid temperature was maintained to be constant during the experiment by placing the lower part of the beaker (up to the $60 \mathrm{~mL}$ mark) in a heated water bath equipped with a thermostat which was set at the desired temperature during the experiment. A clamp used for handling can be seen at the top of the beaker in Fig. 13. As time continues, the foam thickness changes. Fig. 13 shows that the 


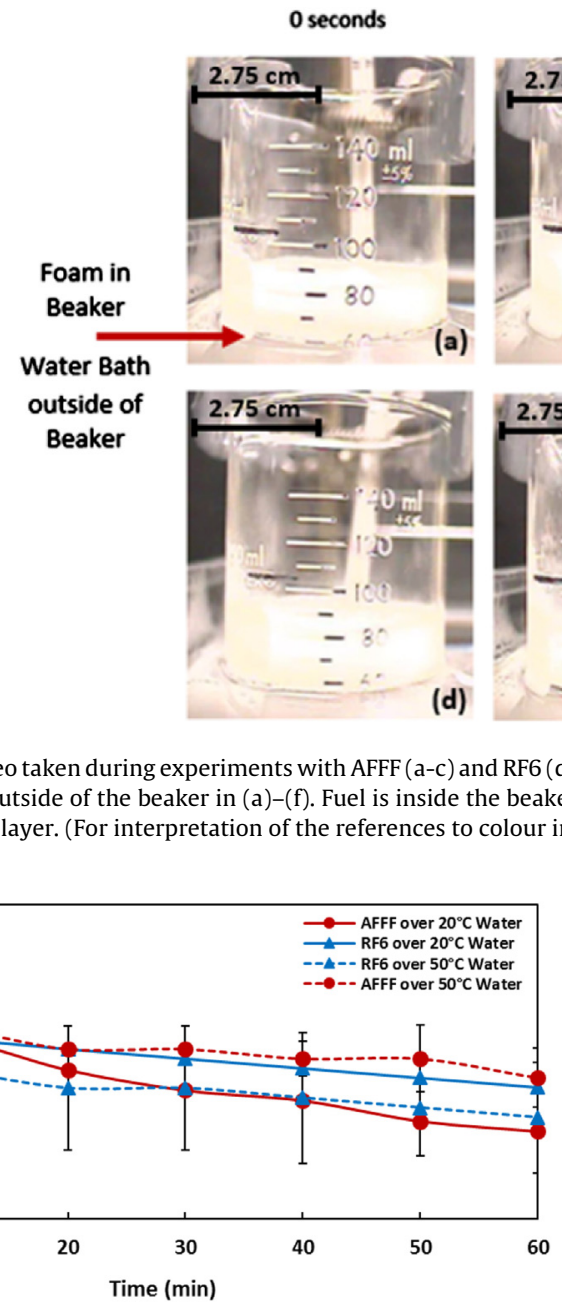

Fig. 14. Foam degradation versus time for AFFF and RF6 foam over water at $50{ }^{\circ} \mathrm{C}$ and room temperature relative to the initial thickness. Initial foam thickness was $1.8-2 \mathrm{~cm}$.

foam thickness is not uniform during the experiment. We measured the foam thickness along the diameter of the container from video recordings using Image software and reported the average value as the foam thickness.

Fig. 14 plots the percent change in foam thickness with time for AFFF and RF6 foam placed over hot water at $50^{\circ} \mathrm{C}$ and at room temperature. Fig. 14 shows that both foams degraded less than $10 \%$ during an hour period over water at $50^{\circ} \mathrm{C}$ and at room temperature. For AFFF, foams over heated water actually degraded slightly less than foams over room temperature water on average; however, the error associated with the measurements concludes that the difference is not statistically significant. The effect of water temperature on degradation is small. Therefore, when the foams are placed on a hot fuel, heat transfer alone is expected to cause less than $10 \%$ degradation in one hour. We observed no increase in foam thickness for AFFF and RF6 placed over water at elevated temperatures. Similar to room temperature measurements, AFFF and RF6 appear to degrade at comparable rates.

Figs. 15 and 16 show the foam degradation rates for AFFF and RF6 foam respectively over heated liquid $n$-heptane. Comparing Figs. 15 and 16, a clear trend emerges as the fuel surface temperature changes. Foam lifetime decreases as the temperature increases as indicated by the change in foam thickness with time for AFFF and RF6 foam layers placed over $n$-heptane. For example, AFFF and RF6 foam degrade faster at $50^{\circ} \mathrm{C}$ than at room temperature over $n$ -

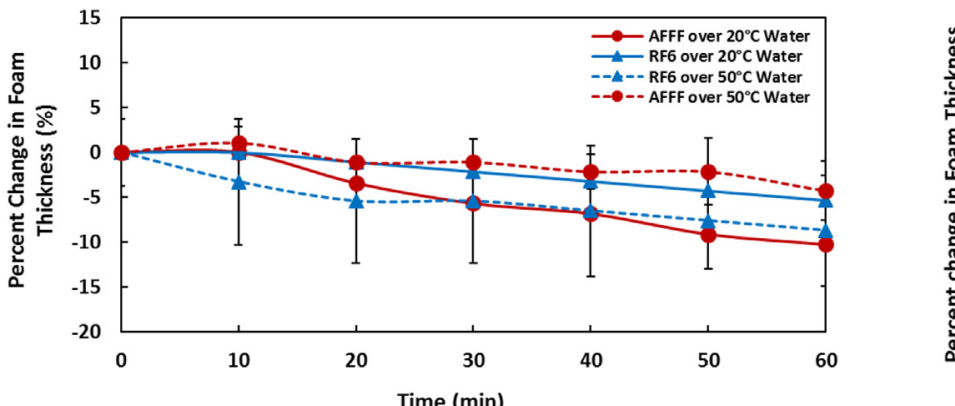

2.7 minutes

4.5 minutes

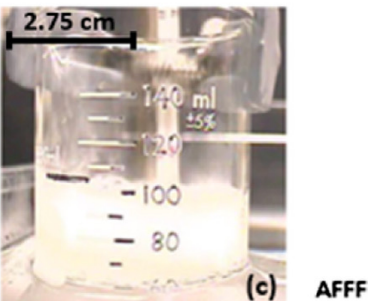

(b)

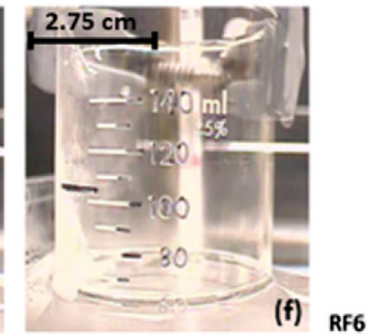

(e)

(f) RF6

(d-f) foam floating on liquid $n$-heptane at an elevated temperature $\left(50{ }^{\circ} \mathrm{C}\right)$. Red line indicates

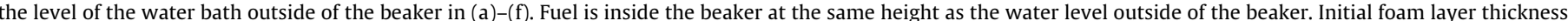

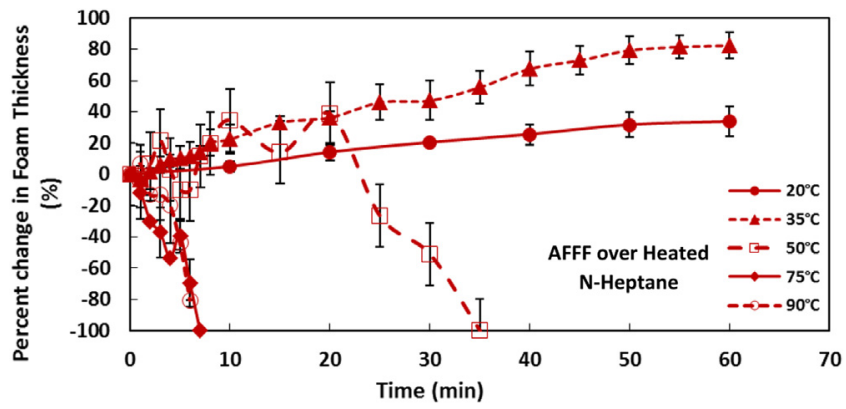

Fig. 15. AFFF foam degradation versus time over $n$-heptane at room temperature, $35,50,75$, and $90^{\circ} \mathrm{C}$. Initial foam thickness was $1.8-2 \mathrm{~cm}$.

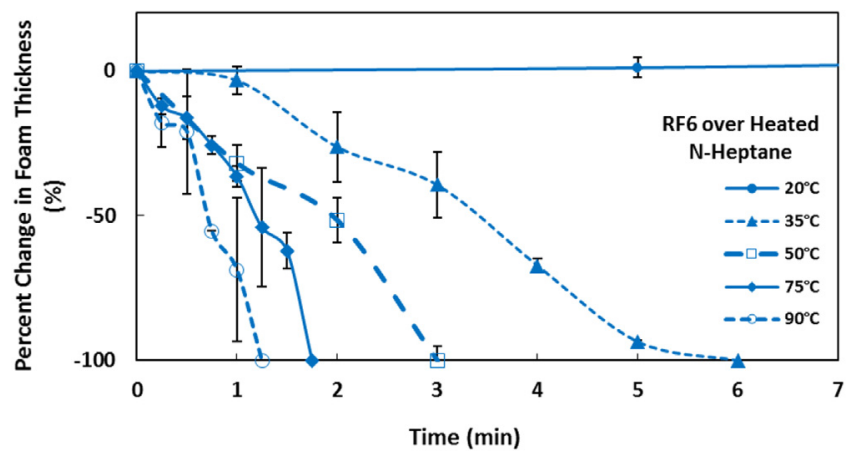

Fig. 16. RF6 foam degradation versus time over $n$-heptane at room temperature, 35 , 50,75 , and $90^{\circ} \mathrm{C}$. Initial foam thickness was $1.8-2 \mathrm{~cm}$.

heptane. The temperature effect is considerable because RF6 and AFFF foam degraded in hours at room temperature, but only in minutes at elevated temperatures. Comparing Figs. 15 and 16 with Fig. 7, the foam lifetime decreased by 13.7 and 75 times for AFFF and RF6 foam respectively as the $n$-heptane temperature is raised from $20^{\circ} \mathrm{C}$ to $50^{\circ} \mathrm{C}$. As the fuel temperature is raised, there is a higher concentration of fuel vapors beneath the foam than at lower temperatures. This increased concentration at the foam interface can increase the amount of fuel transport through the foam, increasing the rate of foam degradation. As discussed above, the heat trans- 


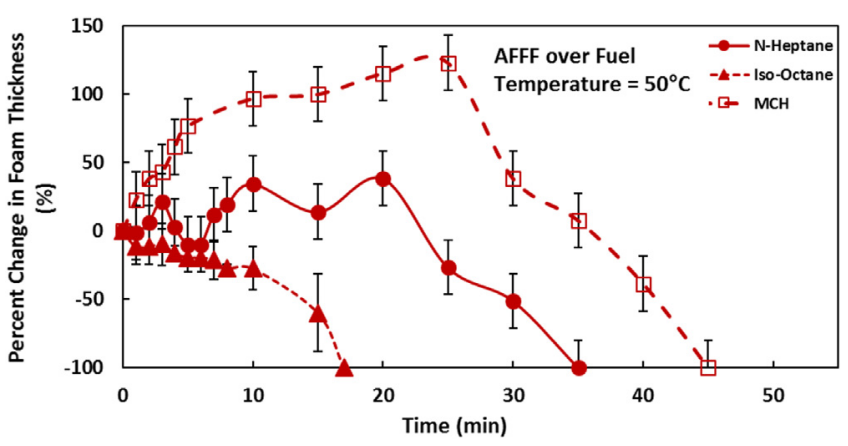

Fig. 17. AFFF foam degradation versus time over heated fuels. Initial foam thickness was $1.8-2 \mathrm{~cm}$.

fer from the hot fuel to foam is expected to have a relatively small (less than 10\%) effect based on the hot water experiments shown in Fig. 14. The fuel temperature effect is by far the largest compared to the effect of different fuels and surfactant formulations (including the additives). The effect of surfactant formulation is a close second relative to the temperature effect; the use of hydrocarbon surfactants in RF6 reduced the foam lifetime by a factor of 17.5 at $50^{\circ} \mathrm{C}$ compared to foams with fluorinated surfactants (AFFF) generated using an identical method of sparging. RF6 foam degrades in $3 \mathrm{~min}$ while AFFF foam degrades in $35 \mathrm{~min}$ at $50^{\circ} \mathrm{C}$. This large difference in foam degradation at elevated temperatures between AFFF and RF6 foam may contribute to the differences in observed fire suppression performance between the two foams [5], especially because the time scale of RF6 foam degradation is comparable to its fireextinction time scale. As discussed previously, degradation of the foam during firefighting reduces the foam's ability to suppress the mass transport of fuel vapor from the underlying liquid fuel pool to the flames above. Both AFFF and RF6 foam exhibit an increased rate of degradation at elevated fuel temperatures, and we believe that this acceleration is due to an increase in the volume of fuel vapor at the foam interface. At $35^{\circ} \mathrm{C}$ and $50^{\circ} \mathrm{C}$, foam expansion was observed for AFFF foam but not for RF6 foam; however, both foams expanded at room temperature. At temperatures higher than $50^{\circ} \mathrm{C}$, AFFF and RF6 foam no longer expand. The increased volume of fuel vapors at the elevated fuel temperatures could be causing the bubbles to rupture at such an increased rate that foam expansion is not seen.

The data shown in Figs. 15 and 16 have significant error bars at elevated temperatures due to uneven bubble dynamics at the fuelfoam interface. Similar to the room temperature interfacial images, large bubbles formed at the foam-fuel interface. At room temperature, these bubbles would coalesce throughout the foam leading to an increased foam thickness represented as foam expansion. However, as temperatures increased, these bubbles formed more rapidly and, instead of coalescing throughout the foam layer leading to expansion, these bubbles would rise to the surface of the foam. The large bubble thickness was accounted for in the foam thickness as seen in Fig. 15 for AFFF foam at $90^{\circ} \mathrm{C}$ when the change in foam thickness appears to increase between 4 and 6 min and in Fig. 16 for RF6 foam at $75^{\circ} \mathrm{C}$ and $90^{\circ} \mathrm{C}$ when the change in foam thickness becomes less steep around 1 and $2 \mathrm{~min}$. The large error is the result of three different experiments with large bubbles forming at different points in time and location.

The increased foam degradation with increased fuel temperature shown in Figs. 15 and 16 can also be seen for the other two fuels, isooctane and $\mathrm{MCH}$, at $50^{\circ} \mathrm{C}$, as shown in Figs. 17 and 18. The foam lifetime for AFFF is affected by the increase in temperature for all 3 fuels, but AFFF foam placed over isooctane still degrades faster than AFFF foam placed over $\mathrm{MCH}$ at elevated temperatures. Fig. 17 shows that AFFF foam lifetime is $62 \%$ and $24 \%$ smaller when placed over isooctane and $n$-heptane respectively relative to that

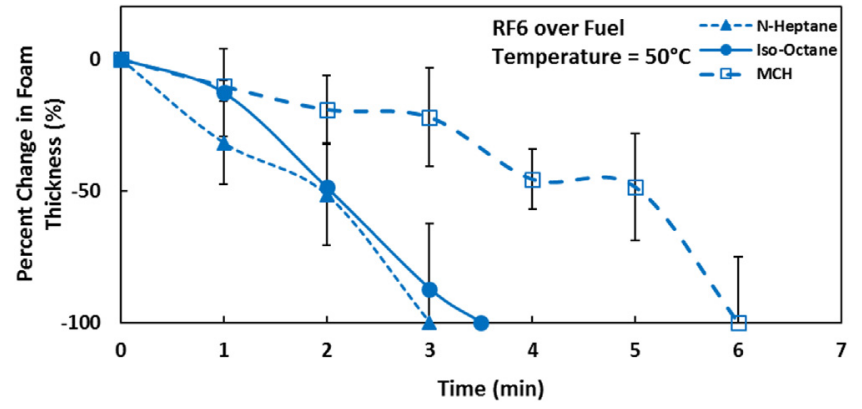

Fig. 18. RF6 foam degradation versus time over heated fuels. Initial foam thickness was $1.8-2 \mathrm{~cm}$.

over $\mathrm{MCH}$ at $50^{\circ} \mathrm{C}$ fuel temperature. A similar trend is seen for RF6 foam over different fuels. But, RF6 foam lifetime is roughly $50 \%$ smaller when placed over either isooctane or $n$-heptane relative to that over $\mathrm{MCH}$ at a fuel temperature of $50^{\circ} \mathrm{C}$ as shown in Fig. 18 . The interactions between surfactant formulation and the fuel are causing these differences between RF6 and AFFF foam, and remain not well understood. However, the differences in foam degradation caused by different fuels shown in Figs. 17 and 18 appear to be smaller relative to the effects of foam formulation when the foams are generated by an identical sparging method. Comparing Figs. 17 and 18 shows RF6 foam degrades faster by factors of 5.8, 10 , and 7.6 for isooctane, $n$-heptane, and $\mathrm{MCH}$ respectively relative to AFFF foam at $50^{\circ} \mathrm{C}$ fuel temperature.

\subsection{Bubble dynamics at foam-fuel interface at elevated fuel temperature}

During the degradation experiments for some trials at elevated temperatures, a single large bubble or "gap" formed between the foam and fuel layer whose volume we included in the measurements of foam thickness. In this section, we discuss the "gap" formation near the foam-fuel interface at elevated temperatures. Fig. 19 displays images from two trials of AFFF foam over $n$-heptane at $50{ }^{\circ} \mathrm{C}$ showing the "gap" formation.

These large bubbles were also observed by Osei-Bonsu et al. [17] at room temperature in which large bubbles would form at random areas of the foam column making foam thickness measurements difficult to quantify. In Osei-Bonsu's experiment, a surfactant solution was mixed with a hydrocarbon and then sparged to create a foam. In more recent experiments using a Hele-shaw column, Osei-Bonsu et al. [21] reported large bubble formation at the foamoil interface. Osei-Bonsu's work and our data show that the large bubbles are caused by the presence of fuel. The foam thickness recorded in the figures of this paper include the "gap" thickness, but the "gap" thickness was also measured separately. For example, Fig. 19(b) shows a large bubble on the left side of the beaker. The foam thickness was inclusive of this large bubble, but because the bubble has not grown to span the entire width of the container forming a "gap", the bubble diameter or "gap" thickness was not measured separately. However in Fig. 19(c), the "gap" has completely separated the foam and the fuel in which the size of this gap over time is now being measured.

"Gap" formation was visibly different from foam expansion. In describing foam expansion, the entire foam thickness expanded as seen in Fig. 5(b) without just a single large bubble causing the expansion. "Gap" formation refers to instances where a single bubble separated the foam layer from the fuel. Complete separation was only seen for AFFF over $n$-heptane and $\mathrm{MCH}$ at $50^{\circ} \mathrm{C}$. In Fig. 20 below, we plot the "gap" volume as a percentage of the total volume recorded, which is calculated as the difference in volume between the bottom surface of the foam layer sitting above the large bubble 


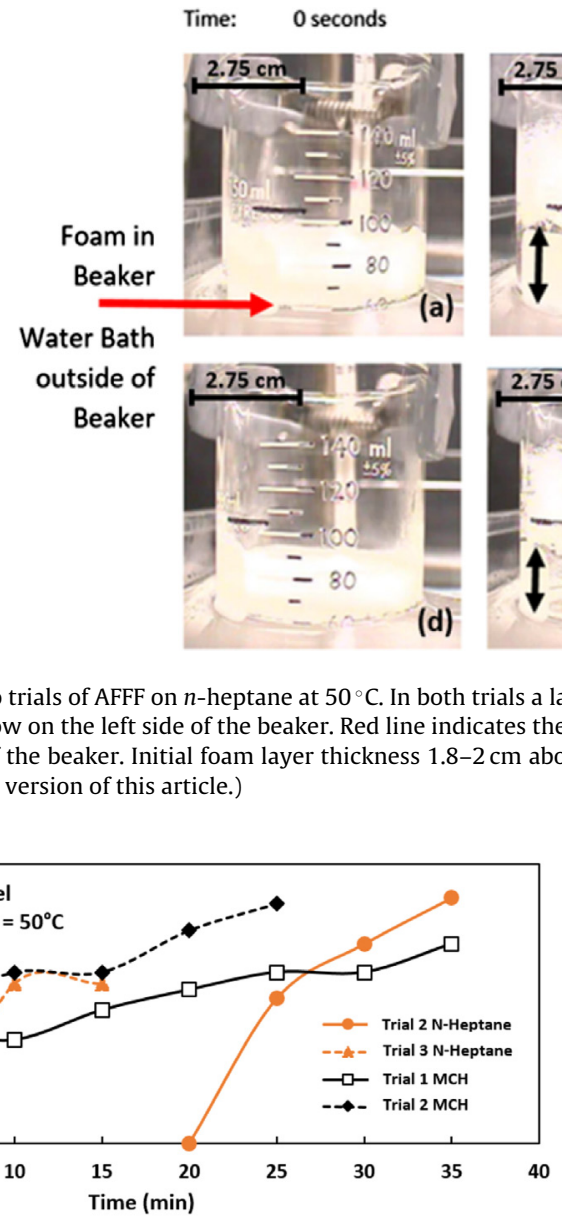

Fig. 20. "Gap" percentage of foam thickness over time of large bubble separation between foam and fuel for different trials of AFFF over heated fuel at $50{ }^{\circ} \mathrm{C}$.

and the surface of the fuel layer, divided by the total volume from the fuel layer to the top of the foam surface. Fig. 20 plots the "gap" volume for two out of three trials for AFFF over liquid $n$-heptane at $50^{\circ} \mathrm{C}$ and two out of three trials for AFFF over liquid $\mathrm{MCH}$ at $50^{\circ} \mathrm{C}$.

Fig. 20 shows that the "gap" formed at different times for each trial with the "gap" comprising over $60 \%$ of the reported foam volume for the four trials with measurable "gap" formation. A bubble separating the foam from the fuel pool formed typically but not in every experimental trial of AFFF foam over $n$-heptane or $\mathrm{MCH}$ at $50^{\circ} \mathrm{C}$; Fig. 20 shows the typical behavior exhibited by the experimental trials that did form a gap and even in cases when a "gap" was not formed, the resulting large bubble at the interface is still comparable to the container width as indicated by Fig. 19(b). This is a significant volume that separates the foam from the fuel layer. Considering the total thickness of the foam layer, the "gap" volume was between 40 and $50 \mathrm{~mL}$. We postulated that the "gap" was actually a very large bubble and had formed from fuel vapors. In an immiscible system, we thought the fuel vapor formed at the interface and may be building up pressure by accumulating in a bubble beneath the foam. To test this, we inserted a pipette through the foam to rupture the "gap" beneath the foam, but inserting the pipette did not release any internal pressure which would have returned the foam to the fuel surface. Instead, the foam remained above the "gap" unaffected by the insertion of the pipette. We also used the pipette to inject air into the "gap". Even after pumping additional air into the "gap", the foam did not return to the fuel surface.

We also considered the air dissolved in the liquid fuel and how the dissolved air may contribute to the volume of the gap. At room temperature, $25 \mathrm{~mL}$ of air can be dissolved in $60 \mathrm{~mL}$ of $n$-heptane
[39]. However, the fuel was preheated on a hot plate indicating most of the dissolved air in the fuel would have been expelled before the foam was placed on the fuel surface, but there could be a small amount of residual air at the elevated temperatures of the fuel beneath the foam. Because of the water bath used to heat the fuel, it was difficult to determine if bubbles were forming in the fuel and traveling to the foam layer. We believe the bulk of the large bubble contains nitrogen from the ruptured bubbles at the interface; nitrogen was used to generate the foams.

Regardless of the composition of the gas in large bubbles that form the "gap", we believe the "gap" formation is due to interactions between the foam and the glass beaker. Our collected data does confirm that large bubbles form at the interface between the foam and the fuel; however, the formation of a single bubble that would completely separate the foam from the fuel interface would not be seen in large scale testing. The gap formation is a result of the small glass beakers used in this experiment where a large bubble can be held in place for long times by the walls of the container. This is supported by Magrabi et al. [7] who points out that foam is a nonNewtonian fluid that can exhibit yield stress, allowing it to undergo wall slip without deforming the column of foam.

To better understand the large bubbles forming at the foam-fuel interface, we filmed interfacial videos at elevated temperatures. Figs. 21 and 22 are time-lapse images of the interface between the foams over $n$-heptane (Fig. 21(a-d) and Fig. 22(a-c)) and water (Fig. 21(e-g) and Fig. 22(d-f)) at $50^{\circ} \mathrm{C}$ for AFFF and RF6 foam respectively. At higher temperatures, the vapor pressure of the fuels increase and a greater amount of fuel vapor escapes from the liquid fuel surface. At higher temperatures, the rate of bubble growth occurs much more rapidly than at room temperature. In Figs. 11 and 12 (room temperature), we see large bubbles forming around $30 \mathrm{~min}$; but, at higher liquid temperatures, bubbles grow in minutes. Comparing Figs. 21 and 22 with Figs. 11 and 12 shows that the higher temperatures accelerate the bubble growth.

The bubble growth and coalescence process is difficult to see in Figs. 21 and 22 because they are simply snapshots of the foam surface at discrete times and do not show migration of bubbles from behind. The videos show the dynamics a little more clearly. Observation of the videos (see supplemental material) confirm the accelerated growth of bubbles on $n$-heptane at $50{ }^{\circ} \mathrm{C}$ compared to that at room temperature. Focusing closely on bubbles adjacent to the foam-fuel interface, the videos showed that all bubbles at 

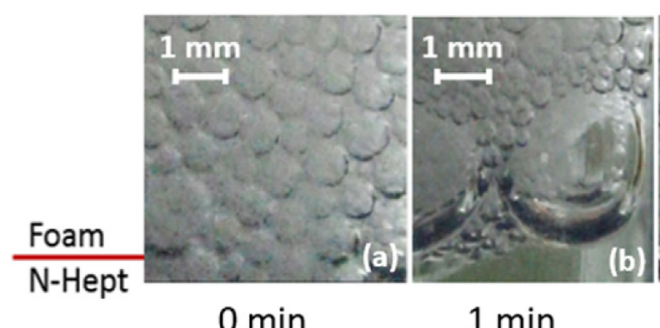

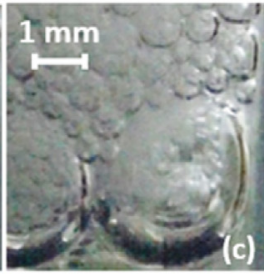

$1.5 \mathrm{~min}$

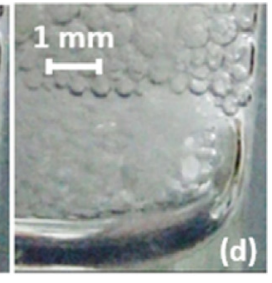

$2 \min$

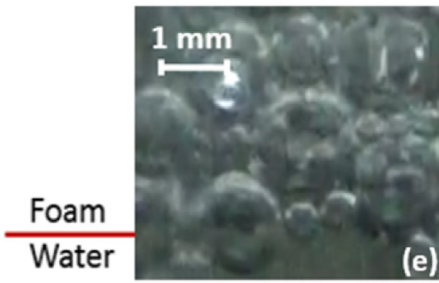

$0 \mathrm{~min}$

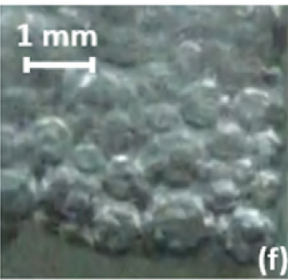

$1 \mathrm{~min}$

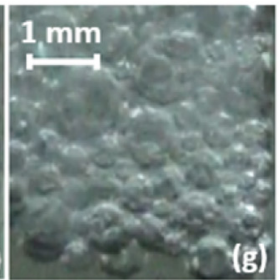

$2 \min$

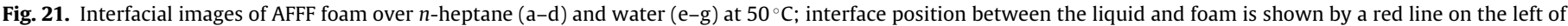
the images. (For interpretation of the references to colour in this figure legend, the reader is referred to the web version of this article.)

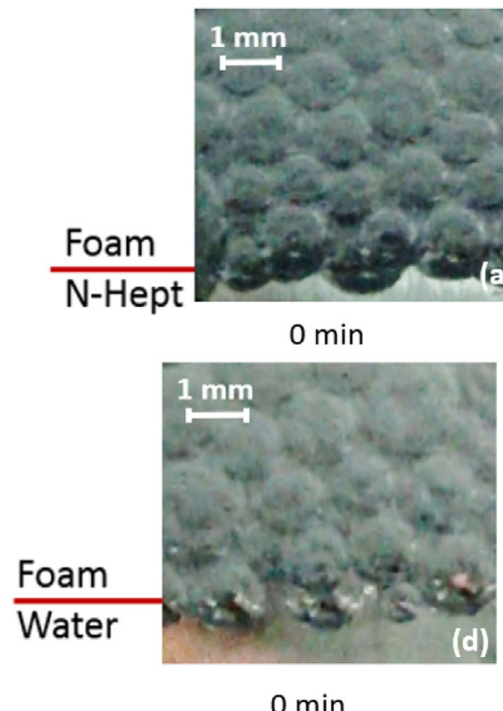

$0 \min$

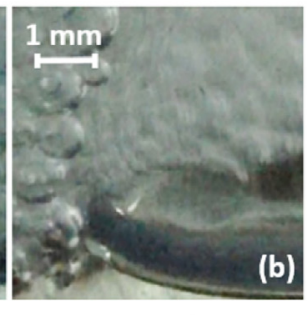

$1 \mathrm{~min}$

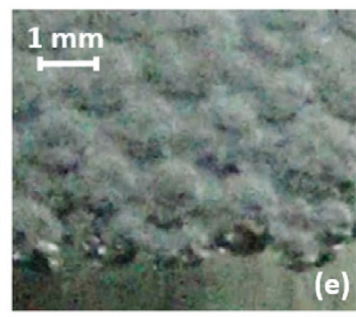

$1 \min$

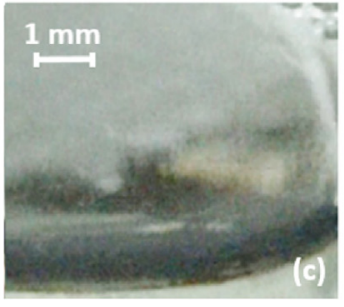

$2 \min$

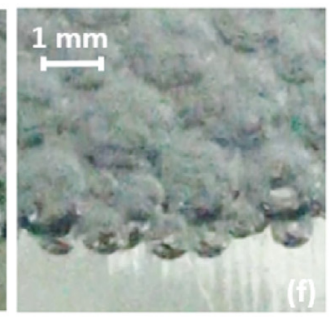

$2 \min$

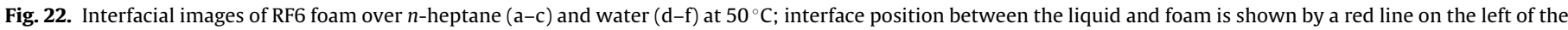
images. (For interpretation of the references to colour in this figure legend, the reader is referred to the web version of this article.)

the interface, large and small, grew but at different rates. We did not notice formation of new bubbles at the interface by the fuel vapor from the hot liquid. Slightly away from the interface the bubbles remained unaffected during the same time period. The videos showed that at some point during the growth, the lamella separating adjacent bubbles ruptured and bubbles coalesced. This process was more rapid in RF6 foam compared to AFFF foam. This is how degradation is initiated at the interface. This cannot be seen in Fig. 21(b) and Fig. 22(b) because the growth and coalescence had already taken place adjacent to the interface and other smaller bubbles away from the interface migrated to the interface.

Even as the temperature increased, Figs. 21 and 22 show that there is no drastic change in bubble diameter when the foams are placed over hot water. In the images of foam placed over hot water, the bubbles at the interface appear to be getting smaller. Because the rapid bubble growth observed for foams placed over $n$-heptane was not observed with hot water, the video observations of bubble growth and the increased rate of foam degradation must be induced by $n$-heptane.
We propose a possible mechanism for the role of fuel in foam degradation that is consistent with our measurements and observations from the videos discussed above. As the fuel temperature is raised, it forms more vapor at the fuel-foam interface. As the fuel vapor enters the foam, it can cool and condense in the foam, which is near room temperature. The condensed fuel can form an immiscible phase on the lamellae separating the bubbles. The additional phase introduces instability in the lamellae and leads to lamellae rupture. This instability has been characterized in research into anti-foaming in which globules of oil/solid are introduced into the foam to cause instability and defoaming $[40,41]$. They describe the behavior of lamella rupturing in the presence of oil as oil bridging in films. Oil can enter a foam film separating a film and create a bridge of oil in a section of the film. The oil presence causes differences in capillary pressure leading the films to stretch until rupture occurs. Additionally, oil can be present in plateau borders. Oil presence compresses plateau borders, increasing the rate of liquid drainage in the foam, ultimately rupturing bubbles in the foam $[40,41]$. 
Thus, as the fuel temperature is raised, the increased amount of vapor forms increased amounts of the condensed fuel in the foam. The increased amount of condensed fuel could cause faster bubble coalescence compared to room temperature. Increased coalescence forms larger bubbles, which increases liquid drainage as shown by Kennedy et al. [8]. As time progresses, both condensed fuel and vapors can travel through the foam into the regions away from the interface and accelerate the naturally occurring coarsening process, where gas can diffuse from relatively smaller bubbles to larger bubbles due to the differences in the curvature and in the composition of gases in adjacent bubbles which may contain different amounts of fuel. The increased coarsening of the bubbles and the associated liquid drainage can lead to degradation of the foam with time [25]. Foams placed on hot water will not lead to increased degradation despite increased vapor pressure and condensation because liquid water is completely miscible with the liquid in the foam. Vapors of fuels (e.g., isooctane) with lower solubility in water tend to form a separate liquid phase on the lamellae more quickly than fuels (e.g., $\mathrm{MCH}$ ) with higher solubility in water. Due to the differences in the solubility in water between fuels, isooctane can lead to faster degradation compared to $\mathrm{MCH}$, consistent with the experimental data presented in Figs. 17 and 18. RF6 foam has relatively larger bubbles than AFFF foam just after they are generated as shown in Table 2. It is expected that differences in bubble diameter distributions between AFFF and RF6 foam will only increase with time, and can lead to increased coalescence and degradation. In addition, the solubility of a fuel can be affected by the surfactant formulation and is not well understood. These differences in solubility and bubble diameter distributions can lead to differences in coalescence of bubbles and degradation for RF6 foam relative to AFFF foam.

\subsection{Effect of initial bubble diameter and expansion ratio}

Earlier, we showed that surfactant formulation has a significant effect on degradation even when the foams are generated by an identical sparging method. The effect of formulation on degradation includes the differences in foam properties induced by changes in the surfactant formulation; the surfactant formulation affects foam properties such as expansion ratio (or liquid content) and bubble diameter as shown in Tables 4 and 5 . The average initial bubble diameters were different between AFFF and RF6 foam: RF6 foam had a bubble diameter $36 \%$ larger than that of AFFF foam. To examine the impact of average initial bubble diameter on foam degradation, we altered the average initial bubble diameter of AFFF and RF6 foam by changing the pore size of the sparger used to generate foam.

By reducing the pore sizes of the sparger from $170-210 \mu \mathrm{m}$ to $10-20 \mu \mathrm{m}$ used to generate the foam (see Fig. 1 ), we were able to reduce the average bubble diameter by more than a factor of 2 ; from $0.54 \mathrm{~mm}$ to $0.3 \mathrm{~mm}$ for AFFF foam and from $0.7 \mathrm{~mm}$ to $0.26 \mathrm{~mm}$ for RF6 foam as shown Table 5. The bubble diameter distributions are expected to be close to those reported by Conroy et al. [42] who used the same generation method described in Section 2.4 but with a sparger having pore sizes $25-50 \mu \mathrm{m}$. Their bubble diameter distributions for RF6 foam also show a bimodal distribution unlike AFFF foam, similar to Figs. 2 and 3. But, changing the pore sizes of the sparger also affected the expansion ratio by almost a factor of 2 as shown in Table 5 which tabulates the expansion ratios of the foam for the two spargers. It is possible that altering the bubble diameter alters the liquid in the foam; therefore, the expansion ratio of the foam is affected by changing bubble diameter consistent with the observation reported by Osei-Bonsu et al. [21]. Osei-Bonsu et al. [21] used different pore size glass discs to generate foams with different bubble diameters and found that the reduced bubble diameter resulted in reduced expansion ratio. Both expansion ratio and bubble diameter can affect liquid drainage in foam. The time

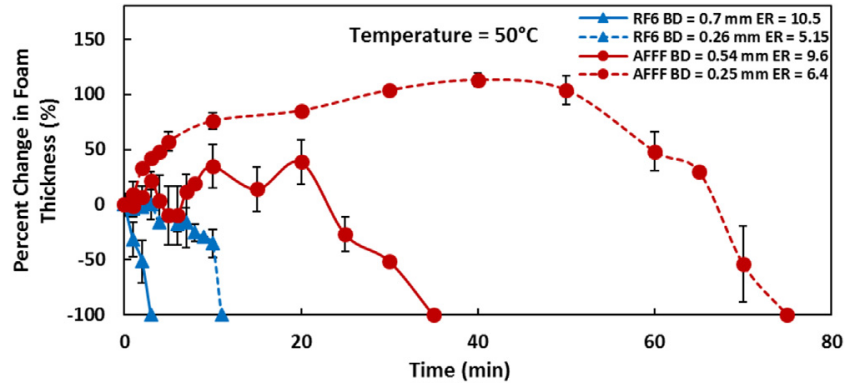

Fig. 23. Foam degradation versus time for AFFF and RF6 foam at two bubble diameters over heated $n$-heptane. Initial foam thickness was $1.8-2 \mathrm{~cm} .170-210 \mu \mathrm{m}$ and $10-20 \mu \mathrm{m}$ spargers were used to generate bubbles. "BD" in the legend refers to the bubble diameter of the foam and "ER" refers to the expansion ratio of the foam.

for $25 \%$ liquid drainage for foam produced with a $10-20 \mu \mathrm{m}$ pore sparger is expected to be smaller than $260 \mathrm{~s}$ in Fig. 4 for AFFF foam, which is for a sprager having $170-210 \mu \mathrm{m}$ pore sizes. Conroy et al. [42] reports an expansion ratio of 5.7 for AFFF foam generated with a $25-50 \mu \mathrm{m}$ sparger, similar to the expansion ratio of AFFF foam generated in our work with a $10-20 \mu \mathrm{m}$ sparger. The $25 \%$ drainage time for AFFF foam generated with a $25-50 \mu \mathrm{m}$ (24 s) reported by Conroy et al. [42] may be close in value to the $25 \%$ drainage time for AFFF foam generated with a $10-20 \mu \mathrm{m}$ sparger in this report.

Fig. 23 shows the change in foam layer thickness for AFFF and RF6 foam placed over $50^{\circ} \mathrm{C} n$-heptane with time for two different bubble diameters and expansion ratios. Fig. 23 shows that reducing the bubble diameter and expansion ratio reduces degradation both for RF6 and AFFF foam. As the bubble diameter is reduced by a factor of 2.7 for RF6, foam lifetime is increased by more than a factor of 3. Similarly, as the bubble diameter is reduced by a factor of 2 , AFFF foam lifetime increased by a factor of 2 . This is consistent with the observations of Osei-Bonsu et al. [21], who reported increased tolerance of foam to oil destruction at a foam-oil interface with reduced bubble diameter and expansion ratio in a Hele-Shaw cell at room temperature. They noted that reduced bubble diameters formed thicker lamellae, which appeared to be more resistant to destabilization and rupture by silicone oil.

Clearly, a significant change in bubble diameter is needed to change the degradation significantly. As explained by Kennedy et al. [8], larger bubbles result in faster drainage, which may increase the rate of foam degradation. Even though the $10-20 \mu \mathrm{m}$ sparger produced AFFF and RF6 foam at similar bubble diameters and at similar expansion ratios, the foam lifetime of AFFF is still significantly longer than RF6 foam. Therefore, differences in bubble diameter cannot explain the large differences, as much as a factor of 10, measured in foam lifetime between AFFF and RF6 shown in Figs. 15 and 16. A further examination of property differences in surfactant formulation and in the interactions between the surfactant formulation and fuel is needed to explain the differences in degradation between AFFF and RF6 foam more comprehensively. However, Fig. 23 clearly shows that reducing bubble diameter and/or expansion ratio can be a way to reduce degradation of foams.

\section{Conclusions}

Foam degradation was measured when a roughly $2 \mathrm{~cm}$ thick foam layer was placed over different fuels and at different fuel temperatures to determine the effect of fuel on foam degradation. This research sought to isolate the effect of fuel on foam degradation to better understand differences between fluorinated and fluorine-free firefighting foams that may impact pool fire suppression performance. We determined that the presence of fuel reduces foam lifetime significantly relative to that on water and that the reduction occurs faster for fluorine-free RF6 foam compared 
to fluorinated AFFF foam. We examined the effects of surfactant formulations (SDS, RF6, and AFFF), different fuels (isooctane, $n$ heptane, and $\mathrm{MCH}$ ), and fuel temperature on degradation of foams.

Data collected at room temperature shows that foam degradation naturally occurs on very long time scales $(10-20 \mathrm{~h})$ and that RF6 foam degraded in a similar time frame to AFFF foam when placed in a glass container without the exposure to fuel or water. A water layer placed underneath the foam prolongs the duration of foam lifetime for AFFF and RF6, but not for SDS. The presence of $n$-heptane at room temperature under AFFF and RF6 foams leads to an increased rate of foam degradation compared to degradation in the control (no liquid under the foam) and water experiment. These experiments show that foam degradation depends on the liquid surface it is covering.

Foam placed over heated fuel degraded significantly faster than foam above room temperature fuel. Foam lifetimes were in hours at room temperature, and only minutes over heated fuel. The effect of fuel temperature is by far the largest on foam degradation, followed by the effects of surfactant formulation, type of fuel, and bubble diameter or expansion ratio. Comparing foam degradation between hot fuel and hot water, we show that the effect of fuel temperature is not because of heat transfer to foam; it is due to the increased vapor pressure of a hydrocarbon liquid. RF6 foam placed over heated fuel degrades in approximately 3 min while AFFF foam degrades in approximately $35 \mathrm{~min}$. AFFF and RF6 foam contain fluorinated and fluorine-free surfactants and different additives; which can affect the solubility of fuel in the aqueous phase of the foam, the bubble diameter, and the expansion ratio despite the identical sparging method used to generate the foams. Reducing sparger pore size reduced bubble diameter by a factor of 2 and decreased the expansion ratio, which increased foam lifetime by a factor of 2 for both the foams. However, RF6 foam degraded faster than AFFF foam for the same average bubble diameter and expansion ratio. Both RF6 and AFFF foam degrade faster when placed on isooctane, followed by $n$-heptane and $\mathrm{MCH}$, which have similar vapor pressures but differ in solubility in water significantly.

Video recording of the foam adjacent to the fuel surface show the formation of large bubbles at the interface between the fuel and foam. These large bubbles are not seen when foam is placed over water. These bubbles grow rapidly due to lamella rupture, which leads to the formation of even larger bubbles. As time progresses, large bubbles lead to faster degradation of the entire foam. This behavior near the interface differs from that of classical coarsening through diffusion in which larger bubbles become larger at the expense of smaller bubbles.

We proposed a possible mechanism for foam degradation that is consistent with collected measurements. Fuel travels through the foam as vapor in the foam bubbles and as condensed liquid in the foam lamella. As fuel transports through the foam, the condensed fuel, with low solubility in water, may create a separate phase along the lamella instead of dissolving into the lamella. This separate phase destabilizes the lamella and can lead to lamella rupture. More soluble fuels will more readily dissolve into the lamella and continue to be transported through the foam with little lamella destabilization. As the lamellae rupture, adjacent bubbles coalesce and become larger. As time passes, larger bubbles cause a foam to drain liquid faster than foams with smaller bubbles [8]. This increased drainage rate can increase the rate of foam degradation [25]. Further studies are needed to quantify the effects of surfactant formulation on fuel solubility, fuel transport, and bubble dynamics in foams to verify the proposed mechanism and especially to explain differences between the degradation of RF6 and AFFF foam. Thus, the reasons remain unclear for the difference in foam degradation rates between fluorinated and fluorine-free foams. Nevertheless, our findings show faster fuel-induced degra- dation of RF6 foam may contribute significantly to its inferior fire suppression performance relative to AFFF foam.

\section{Acknowledgments}

We would like to acknowledge Dr. Bradley Williams and Dr. James W. Fleming, formerly of the Naval Research Laboratory, for their expertise and advice as well as Dr. Arthur Snow. We also thank the Office of Naval Research for supporting this work through the Naval Research Laboratory.

\section{Appendix A. Supplementary data}

Supplementary data associated with this article can be found, in the online version, at http://dx.doi.org/10.1016/j.colsurfa.2017.02. 082 .

\section{References}

[1] S. Oresky, D. DeYoung, T. Coffey, The Little Book of Big Achievements, Naval Research Laboratory, NRL, 2000, pp. 14.

[2] J.L. Scheffey, J.T. Leonard, AFFF protection from weapons staging areas, Fire Saf. J. 14 (1-2) (1998) 47-63.

[3] Military Specification: Fire Extinguishment Agent. Aqueous Film-Forming Foam (AFFF) Liquid Concentrate, For Fresh and Sea Water MIL-F-24385F, Naval Sea System Command (1992).

[4] S. Zhang, D.N. Lerner, Review of physical and chemical properties of perfluorooctanyl sulphonate (PFOS) with respect to its potential contamination on the environment, Adv. Mater. Res. Switz. 518-523 (2012) 2183-2191

[5] B. Williams, C. Butterworth, Z. Burger, R. Sheinson, J. Fleming, C. Whitehurst, J. Farley, Extinguishment and Burnback tests of fluorinated and fluorine-free firefighting foams with and without film formation, in: Suppression, Detection, and Signaling Research and Applications-A Technical Working Conference, NFPA, Orlando, FL, 2011.

[6] E. Iglesias, J. Anderez, A. Forgiarini, J.-L. Salager, A new method to estimate the stability of short-lifetime foams, Colloids Surf. A 98 (1995) 167-174.

[7] S.A. Magrabi, B.Z. Dlugogorski, G.J. Jameson, A comparative study of drainage characteristics in AFFF and FFFP compressed-air fire-fighting foams, Fire Saf. J. 37 (1) (2002) 21-52

[8] M. Kennedy, M. Conroy, J. Dougherty, N. Otto, B. Williams, R. Ananth, J. Fleming, Bubble coarsening dynamics in fluorinated and non-fluorinated firefighting foams, Colloids Surf. A 470 (2015) 268-279.

[9] M.U. Vera, D.J. Durian, Enhanced drainage and coarsening in aqueous foams, Phys. Rev. Lett. 88 (8) (2002) 088304

[10] H.A. Stone, S.A. Koehler, S. Hilgenfeldt, M. Durand, Perspectives on foam drainage and the influence of interfacial rheology, J. Phys.: Condens. Matter 15 (2003) S283-S290.

[11] A. Saint-Jalmes, Y. Zhang, D. Langevin, Quantitative description of foam drainage: transitions with surface mobility, Eur. Phys. J. E 15 (1) (2004) 53-60.

[12] A. Saint-Jalmes, Physical chemistry in foam drainage and coarsening, R. Soc. Chem. Soft Matter 2 (2006) 836-849.

[13] P.M. Kruglyakov, S.I. Karakashev, A.V. Nguyen, N.G. Vilkova, Foam drainage, Curr. Opin. Colloids Interface Sci. 13 (2008) 163-170

[14] S.A. Magrabi, B.Z. Dlugogorski, G.J. Jameson, Bubble size distribution and coarsening of aqueous foams, Chem. Eng. Sci. 54 (18) (1999) 4007-4022.

[15] H. Do, M. Brady, D.P. Telionis, P.P. Vlachos, R.H. Yoon, Numerical modeling and experiments of coarsening foam, Int. J. Miner. Process. 98 (1-2) (2011) 66-73.

[16] S. Hilgenfeldt, S.A. Koehler, H.A. Stone, Dynamics of coarsening foams: accelerated and self-limiting drainage, Phys. Rev. Lett. 86 (20) (2001) 4704-4707.

[17] K. Osei-Bonsu, N. Shokri, P. Grassia, Foam stability in the presence and absence of hydrocarbons: from bubble- to bulk-scale, Colloids Surf. A 481 (2015) 514-526.

[18] A.K. Vikingstad, A. Skauge, H. Hoiland, M. Aarra, Foam-oil interactions analyzed by static foam tests, Colloids Surf. A 260 (2005) 189-198.

[19] A.K. Vikingstad, M.G. Aarra, A. Skauge, Static and dynamic studies of foam and foam-oil interactions, Colloids Surf. A 279 (2006) 105-112.

[20] M. Simjoo, T. Rezaei, A. Andrianov, P.L.A. Zitha, CT scan study of immiscible foam flow in porous media for enhancing oil recovery, Colloids Surf. A 438 (2014) 148-158.

[21] K. Osei-Bonsu, P. Grassia, N. Shokri, Fundamental investigation of foam flow in porous media in the presence of oil, J. Colloid Interface Sci. 462 (2016) 288-296 (Accepted).

[22] Foams: Basic Principles, Foams: Fundamentals and Applications in the Petroleum Industry, in: L.L. Schramm, F. Wassmuth, L.L. Schramm (Eds.), ACS, 1994, pp. 3-45.

[23] L.L. Schramm, J.J. Novosad, The destabilization of foams for improved oil recovery by crude oils; effect of the nature of the oil, J. Petrol. Sci. Eng. 7 (1992) 77-90. 
[24] C.F. Boyd, M. Di Marzo, The behavior of a fire-protection foam exposed to radiant heating, Int. J. Heat Mass Transf. 41 (12) (1998) 1719-1728

[25] B. Lattimer, C. Hanauska, J. Scheffey, F. Williams, The use of small-scale test data to characterize some aspects of firefighting foam for suppression modeling, Fire Saf. J. 38 (2003) 117-146.

[26] ScienceLab.com (2013) 2,2,4-Trimethylpentane [Data File]. Retrieved from https://www.sciencelab.com/msds.php? msdsId=9927418 (2016).

[27] ScienceLab.com (2013) N-heptane [Data File]. Retrieved from http://www. sciencelab.com/msds.php? msdsId=9924237 (2016).

[28] ScienceLab.com (2013) Methylcyclohexane [Data File]. Retrieved from https://www.sciencelab.com/msds.php?msdsId=9924678 (2016).

[29] Royal Society of Chemistry (2011) Substance: 2,2,4-Trimethylpentane [Dat File]. Retrieved from http://www.rsc.org/learn-chemistry/wiki/ Substance:2,2,4-Trimethylpentane (2016).

[30] Royal Society of Chemistry (2011) Substance: heptane [Data File]. Retrieved from http://www.rsc.org/learn-chemistry/wiki/N-HEPTANE (2016).

[31] Royal Society of Chemistry (2011) Substance: methylcyclohexane [Data File]. Retrieved from http://www.rsc.org/learn-chemistry/wiki/Methylcyclohexane (2016).

[32] B. Jajuee, A. Margaritis, D. Karamaev, M.A. Bergougnou, Influence of dissolved hydrocarbons on volumetric oxygen mass transfer coefficient in a novel airlift contactor, Chem. Eng. Sci. 61 (2006) 4111-4119.

[33] B.Z. Dlugogorski, S. Phiyanalinmat, E.M. Kennedy, Dynamic surface and interfacial tension of AFFF and fluorine-free class B foam solutions, Fire Safety Science-Proceedings of the 8th International Symposium (2005) 719-730.

[34] T.H. Schaefer, Aqueous Foaming Composition, PCT/US02/38937, WO 03/049813 A1, World Intellectual Property Organization, 2003, pp. 22.
[35] Monararfs.com (2006) FC-203A Light Water ${ }^{\mathrm{TM}}$ Brand Aqueous Film Forming Foam [Data File]. Retrieved from http://www.monarorfs.org.au/index. php?option=com_phocadownload\&view=category\&download=12:aqueousfilm-forming-foam-afff\&id=7:msds-documents\&Itemid=388 (2016).

[36] SigmaAldrich.com (2015) Sodium Dodecyl Sulfate [Data File]. Retrieved from http://www.sigmaaldrich.com/MSDS/MSDS/DisplayMSDSPage. do? country=US\&language=en\&productNumber=862010\&brand=ALDRICH\&Page ToGoToURL=http\%3A\%2F\%2Fwww.sigmaaldrich. com\%2Fcatalog\%2Fproduct\%2Faldrich\%2F862010\%3Flang\%3Den (2016).

[37] M.W. Conroy, R. Ananth, Fuel surface cooling by aqueous foam: a pool fire suppression mechanism, Fire Technol. 51 (3) (2015) 667-689.

[38] R. Mensire, K. Piroird, E. Lorenceau, Capillary imbibition of aqueous foams by miscible and nonmiscible liquids, Phys. Rev. E 92 (2015) 053014

[39] R. Battino, T.R. Rettich, T. Tominaga, The solubility of oxygen and ozone in liquids, J. Phys. Chem. 12 (2) (1983), Retrieved from http://www.nist.gov/ data/PDFfiles/jpcrd219.pdf.

[40] N. Denkov, P. Cooper, J. Martin, Mechanisms of action of mixed solid-liquid antifoams. 1. Dynaics of foam film rupture, Langmuir 15 (1999) 8514-8529.

[41] P.R. Garrett, The Science of Defoaming: Theory, Experiment and Applications, CRC Press, Boca Raton, 2013.

[42] M. Conroy, J. Flemming, R. Ananth, Surface cooling of a pool fire by aqueous foams, Combust. Sci. Technol. (2017) (in press). 